\title{
Viability Study of a Safe Method for Health to Prepare Cement Pastes with Simultaneous Nanometric Functional Additions
}

\author{
M. A. de la Rubia $\mathbb{D},{ }^{1}$ E. de Lucas-Gil $\mathbb{D},{ }^{2}$ E. Reyes, ${ }^{1}$ F. Rubio-Marcos $\mathbb{D},{ }^{2}$ \\ M. Torres-Carrasco, ${ }^{2}$ J. F. Fernández, ${ }^{2}$ and A. Moragues ${ }^{1}$ \\ ${ }^{1}$ Department of Civil Engineering-Construction, School of Civil Engineering, Polytechnic University of Madrid, \\ C/Professor Aranguren s/n, 28040 Madrid, Spain \\ ${ }^{2}$ Electroceramic Department, Instituto de Cerámica y Vidrio (CSIC), C/Kelsen 5, 28049 Madrid, Spain
}

Correspondence should be addressed to M. A. de la Rubia; ma.rubia@caminos.upm.es

Received 19 December 2017; Revised 14 March 2018; Accepted 27 March 2018; Published 6 May 2018

Academic Editor: Antonio Gilson Barbosa de Lima

Copyright $\left({ }_{0} 2018\right.$ M. A. de la Rubia et al. This is an open access article distributed under the Creative Commons Attribution License, which permits unrestricted use, distribution, and reproduction in any medium, provided the original work is properly cited.

\begin{abstract}
The use of a mixing method based on a novel dry dispersion procedure that enables a proper mixing of simultaneous nanometric functional additions while avoiding the health risks derived from the exposure to nanoparticles is reported and compared with a common manual mixing in this work. Such a dry dispersion method allows a greater workability by avoiding problems associated with the dispersion of the particles. The two mixing methods have been used to prepare Portland cement CEM I 52.5R pastes with additions of nano- $\mathrm{ZnO}$ with bactericide properties and micro- or nanopozzolanic $\mathrm{SiO}_{2}$. The hydration process performed by both mixing methods is compared in order to determine the efficiency of using the method. The hydration analysis of these cement pastes is carried out at different ages (from one to twenty-eight days) by means of differential thermal analysis and thermogravimetry (DTATG), X-ray diffraction (XRD), scanning electron microscopy (SEM), and Fourier transform infrared spectroscopy (FTIR) analyses. Regardless of composition, all the mixtures of cement pastes obtained by the novel dispersion method showed a higher retardation of cement hydration at intermediate ages which did not occur at higher ages. In agreement with the resulting hydration behaviour, the use of this new dispersion method makes it possible to prepare homogeneous cement pastes with simultaneous functional nanoparticles which are physically supported on the larger particles of cement, avoiding exposure to the nanoparticles and therefore minimizing health risks. Manual mixing of cement-based materials with simultaneous nanometric functional nanoparticles on a large scale would make it difficult to obtain a homogenous material together with the health risks derived from the handling of nanoparticles.
\end{abstract}

\section{Introduction}

Cement is the most used binder material in construction and building, with it mainly being a fundamental component of mortar and concrete. The microstructure and functional behaviour of cement-based materials strongly depend on the chemical composition and additions, water-cement ratio, and rate of hydration. The incorporation of additions to modify and improve its fresh properties and its physical, mechanical, and durability properties, as well as to obtain new functional properties such as photocatalysis $[1,2]$, antibacterial effects (Sikora et al. [3, 4]), hydrophobicity (Tittarelli [5] and Nunes and Slizkova [6]), and fungicide effects (De Muynck et al. [7]) among others is currently an important research topic. In recent years, nanotechnology applied to cement-based materials has been growing since the use of additions of nanometric size significantly increases the effects on their mechanical and functional properties, and the combination of several additions might be very promising (Sikora et al. [4], León et al. [8], and Mohseni et al. [9]). However, the simultaneous addition of several functional nanoparticles simultaneously is an even greater challenge due to their tendency to agglomeration and by the risk to health during its manipulation (Vishwakarma et al. [10], Albrecht et al. [11], and Mueller and Nowack [12]).

In the case of the addition of silica, the pozzolanic activity and filling capacity are the two main characteristics that significantly influence the cement-based material properties (Haruehansapong et al. [13], Senff et al. [14], and $\mathrm{Lu}$ and Poon [15]). Pozzolanic materials provide an increase 
in the amount of calcium-silicate-hydrate (CSH) gels, as well as a denser and more discontinuous and tortuous microstructure via pozzolanic reactions. As a result, an improvement of the mechanical and durable properties of the cement-based materials occurs (Massana et al. [16] and Ramezanianpour and Moeini [17]). A significant factor is the distribution particle size of silica, related with the specific surface. Silica fume is a by-product and generally shows a wide particle size range from submicronic particles to a few tens of microns. In contrast, in the case of nanosilica, the particle size is lesser. Smaller sized particles provide nucleating sites to hydration products since the high surface area, particularly in the case of nanosilica, allows the formation of calcium-silicate-hydrate (CSH) gel seeds on its surface formed by an early pozzolanic reaction that accelerate silicate hydration (Cheng-yi and Feldman [18], Larbi et al. [19], Thomas et al. [20], and Land and Stephan [21]). The surface area of silica becomes higher so does the acceleration of hydration (Land and Stephan [21]).

Zinc oxide, $\mathrm{ZnO}$, can present three crystalline structures, with the most stable being the hexagonal structure, wurtzite. $\mathrm{ZnO}$ is an n-type semiconductor with a band gap of $3.2 \mathrm{eV}$ at room temperature $\mathrm{RT}$. $\mathrm{ZnO}$ is produced directly by oxidizing zinc metal, a reduction of an ore to zinc metal followed by re-oxidation and to a lesser extent, by precipitation of oxide or carbonate from aqueous solution and a final thermal treatment (Moezzi et al. [22]). This oxide has a large number of applications, with a vulcanization activator in the rubber industry being the main function. $\mathrm{ZnO}$ is a highly important raw material in ceramics (glazes and enamels in tiles and sanitary ware), in electroceramics such as overvoltage protection devices (varistors) (Sendi [23] and Xu [24]), and in optoelectronics (Kahouli et al. [25], Hussein et al. [26], and Torchynska et al. [27]). It is currently being researched as a photocatalyst and novel antifungal precursor. The morphology of the $\mathrm{ZnO}$ particles mainly depends on the synthesis techniques, precursors, process conditions, and $\mathrm{pH}$ (Moezzi et al. [22]).

According to Klingshirn, the use of $\mathrm{ZnO}$ particles in concrete increases the setting time and, therefore, the workability for early ages, and provides an improvement in its resistance against water (Klingshirn [28]). The main effects of zinc oxide additions to the Portland cement have been known for some time: retardation of setting and hardening (reducing the rate of heat evolution) leads to an improvement in whiteness and final strength (Ramachandran [29]). Recently, authors such as Nivethitha et al. have suggested that the addition of nano- $\mathrm{ZnO}$ particles may also improve the mechanical properties of ordinary Portland cement mortar (Nivethitha and Dharmar [30]).

Several authors have studied the influence of $\mathrm{ZnO}$ on the hydration of the Portland cement. Arliguie showed that the delay in hydration is due to the precipitation of an amorphous $\mathrm{Zn}(\mathrm{OH})_{2}$ layer around the anhydrous $\mathrm{C}_{3} \mathrm{~S}$ grains which inhibits cement dissolution (Arliguie and Grandet [31]). The hydration of $\mathrm{C}_{3} \mathrm{~A}$ in the presence of $\mathrm{ZnO}$ occurs too, when there is a significant presence of $\mathrm{SO}_{3}$. When the pore concentration of $\mathrm{Ca}^{2+}$ and $\mathrm{OH}^{-}$is enough, the hydration reaction starts again and the amorphous $\mathrm{Zn}(\mathrm{OH})_{2}$ layer transforms into crystalline calcium zinc hydroxide $\mathrm{CaZn}_{2}(\mathrm{OH})_{6} \cdot 2 \mathrm{H}_{2} \mathrm{O}$ (CZ) (Arliguie and Grandet [31]). Yousuf et al. identified a calcium zinc hydroxide crystalline phase by means of Fourier transform infrared spectroscopy (FTIR) in paste samples with $\mathrm{ZnO}$ cured for 28 days (Yousuf et al. [32]). Some authors corroborate the formation of this calcium hydroxyzincate dihydrate $\mathrm{CaZn}_{2}(\mathrm{OH})_{6} \cdot 2 \mathrm{H}_{2} \mathrm{O}(\mathrm{CZ})$, suggesting that the formation of this phase controls $\mathrm{Zn}$ solubility in cementitious materials (Cocke et al. [33]). Johnson and Kersten showed that solid solution is a possible binding mechanism for $\mathrm{Zn}$ (II) in the CSH gel, indicating that at least $10 \%$ of $\mathrm{Zn}$ may be incorporated in the $\mathrm{CSH}$ structure (Johnson and Kersten [34]). In such a way, Lieber and Gebauer confirmed the formation of crystalline calcium hydroxyzincate during the retardation period as an intermediate product (though after some days of reaction, it is no longer detectable) (Lieber and Gebauer [35]). In a recent study, Ataie et al. [36] in contrast with Arliguie, indicated that the mechanism by which $\mathrm{ZnO}$ retards hydration reaction could be nucleation and/or growth poisoning of CSH and suggested that $\mathrm{ZnO}$ does not inhibit cement dissolution. Ataie showed that $\mathrm{ZnO}$ strongly delays the cement hydration and the retardation increases as the $\mathrm{ZnO}$ quantity in the cement rises, so the amount of $\mathrm{ZnO}$ added is directly correlated with such an increase in the retardation period. $\mathrm{Zn}$ ions hinder nucleation and growth of hydrated products poisoning the hydration product nuclei. When there are not enough dissolved $\mathrm{Zn}$ ions, retardation ends and a greater acceleration of hydration occurs. In the same sense, various authors suggest that the $\mathrm{CSH}$ gel is the most probable site for metal fixation in cement and $\mathrm{Zn}^{2+}$ is incorporated in the interlayer CSH (Stumm et al. [37], Ouki and Hills [38], Ziegler et al. [39], and Ziegler and Johnson [40]).

Therefore, calcium hydroxyzincate dihydrate $\mathrm{CaZn}_{2}(\mathrm{OH})_{6} \cdot 2 \mathrm{H}_{2} \mathrm{O}(\mathrm{CZ})$ has an important influence in the retardation of the Portland cement hydration (Arliguie and Grandet [31]) and in the prevention from corrosion of the galvanized steel in concrete when this hydroxyzincate phase forms a coating on the rebars (Tittarelli and Bellezze [41]). Protection against corrosion is due to the formation of a compact and protective layer of this phase at high $\mathrm{pH}$ values between 12.2 and 13.3.

$\mathrm{ZnO}$ and compounds such as $\mathrm{CaZn}_{2}(\mathrm{OH})_{6} \cdot 2 \mathrm{H}_{2} \mathrm{O}$ are being researched as antifungal, bactericide, and photocatalyst materials (Xie et al. [42], Sirelkhatim et al. [43], Madhusudhana et al. [44], Gomez-Ortiz et al. [45], and Hernandez Sierra et al. [46]). Gomez-Ortiz et al. used CZ as the antifungal precursor of protective coatings for marble and limestone (Gomez-Ortiz et al. [45]). A drawback when using both $\mathrm{ZnO}$ and $\mathrm{SiO}_{2}$ nanoparticles as an addition in the Portland cement may involve the requirement of a greater amount of mixing water due to a greater amount of fines, which increases the water-cement ratio. The use of superplasticizers is common in order to improve the workability.

Nanoparticles, due to their high specific surface area, have a high tendency to form agglomerates. Such agglomeration drastically reduces the effectiveness and modifies the properties regarding the dispersed state of nanoparticles avoiding obtaining homogeneous mixtures. Therefore, agglomeration 
should be avoided in order to achieve homogeneous admixtures using a low amount of nanoparticles and minimizing the health risks derived from its management. The difficulty in avoiding the agglomeration of functional nanoparticles and the difficulty in obtaining a material with high homogeneity increase in manual mixing when trying to introduce several additions simultaneously in cement pastes. Manual mixing to achieve homogeneous admixtures implies an increase in exposure time to nanoparticles and therefore an increase in health risks.

Nanotechnology is increasingly used in production processes. Currently, it is difficult to determine the risks to health and the environment during handling in the preparation of composites. Because of this, it is infeasible to prepare cement-based materials with functional nanoadditions (silica, zinc oxide, and titania, among others) at an industrial level by a manual mixing method to achieve a homogeneous dispersion of functional nanoparticles, given that they have a high health risk due to a small particle size. Therefore, in order to minimize health risks derived from the use of nanoparticles, it is necessary to minimize exposure time and handling. The patented low-energy dry dispersion method (Fernandez Lozano et al. [47]) allows the nanoparticles to be incorporated in an effective way, by simplifying the steps, avoiding exposure, and handling nanoparticles, as the dispersion of the nanoparticles takes place on dry larger particles (cement particles). These nanoparticles are supported on the cement particles by cohesive forces, thus avoiding or decreasing spreading. A consistent powder with a particle distribution consisting of nanoparticles dispersed and anchored by short-range forces on particles of different morphologies is obtained. Such short-range forces avoid the presence of free nanoparticles when the composite powder is handled or used, decreasing the health risk. This process is in the absence of solvents (dry process) and does not require high shear rates. Implementation of such a process would be viable at an industrial level in a cement production plant.

The object of this study, therefore, is to assess the feasibility of preparing homogeneous functional cement-based powders with simultaneous functional nanoadditions $\left(\mathrm{SiO}_{2}\right.$ and $\mathrm{ZnO}$ ) by means of an easy-to-use dry dispersion method minimizing health risks and avoiding exposure to nanoparticles during the preparation of cement pastes.

\section{Materials and Methods}

2.1. Materials. The cement paste is a $52.5 \mathrm{R}$ Type I commercial Portland cement with a particle size $d_{50}$ of $6.3 \mu \mathrm{m}$ and specific surface of $1.45 \mathrm{~m}^{2} / \mathrm{g}$. The nanometric $\mathrm{ZnO}$ was obtained as a product of hydrozincite $\left(\mathrm{Zn}_{5}\left(\mathrm{CO}_{3}\right)_{2}(\mathrm{OH})_{6}\right)$ calcination at $500^{\circ} \mathrm{C}$ for five minutes in air. The XRD characterization indicates that the phase matches the hexagonal wurtzite structure $\mathrm{ZnO}$ (JCPDS card number 36-1451), without peaks, of other phases. The nanometric $\mathrm{ZnO}$ shows a specific surface area of $18.59 \mathrm{~m}^{2} / \mathrm{g}$ determined by the Brunauer-EmmettTeller (BET) method and a monomodal distribution with an average particle size of $53 \mathrm{~nm}$ from field emission scanning electron microscopy FE-SEM micrographs. The micrometric
$\mathrm{SiO}_{2}$ (MS) used is silica fume produced in the manufacturing of ferro-silicon alloy. It is noncrystalline silica with wide distribution particle sizes with a $d_{50}$ of $45.2 \mu \mathrm{m}$ and a specific surface area of $28.52 \mathrm{~m}^{2} / \mathrm{g}$. Microsilica contains $91 \mathrm{wt} . \%$ of $\mathrm{SiO}_{2}$ and 5.3 wt.\% of $\mathrm{Fe}_{2} \mathrm{O}_{3}$.

The nanometric $\mathrm{SiO}_{2}$ (NS) Sipernat ${ }^{\circledR} 22 \mathrm{~S}$ from Evonik Industries [48] is manufactured hydrophilic silica in a liquid-phase precipitation process that obtains aggregates with a micrometer size of $14 \mu \mathrm{m}$ composed of tiny primary particles $(5-100 \mathrm{~nm})$. The advantages of using Sipernat $22 \mathrm{~S}$ involve an amorphous structure and a high surface area of $180 \mathrm{~m}^{2} / \mathrm{g}$. Sipernat $22 \mathrm{~S}$ increases the early strength and consistency of concrete, reduces bleeding and segregation in self-compacting concrete, and has a hydrophobic effect that improves the water resistance of concrete (Aerosil, Aeroxide, and Sipernat products, Evonik Industries, Technical Information). Due to the difference between the specific surface area of microsilica (MS) and nanosilica (NS), the pozzolanic reactivity of nanosilica Sipernat is much higher. Both have an acidic character.

2.2. Sample Preparation. Three cement paste mixtures were studied, including 52.5R Type I Portland cement and different combinations of additions of nano- $\mathrm{ZnO}$ (NZ), nanosilica, and microsilica as a substitute of anhydrous cement: one with 2 wt.\% of nano- $\mathrm{ZnO}(\mathrm{NZ})$, another with 2 wt.\% of nano- $\mathrm{ZnO}(\mathrm{NZ})$ and 10 wt.\% of nanosilica (NS), and the last one with 2 wt.\% nano-ZnO (NZ) and 10 wt.\% of microsilica (MS). The mixtures were prepared by two mixing methods. A first mixing method involved a common manual mixing. The other mixing method used was the dispersion of the different functional particles (nano- $\mathrm{ZnO}$, microsilica, and nanosilica) over the 52.5R Type I Portland cement particles, using the aforementioned low-energy dry dispersion (low shear rate) novel method (Fernandez Lozano et al. [47]). In this method of dry dispersion, the cement particles as the different additions were dried and then mixed in a Turbula-type shaker with $15 \mathrm{~mm}$ diameter alumina balls (Lorite et al. [49] and Alonso-Domínguez et al. [50]). The water-cement ratio was fixed at 0.35 for the admixtures except for that which had 2 wt.\% nano-ZnO (NZ) +10 wt. \% nanosilica with a ratio fixed at 0.6 since nanosilica has a high specific surface and demands more water to obtain complete hydration of the mixture.

In order to obtain good rheological properties such as flowability but without segregation, a policarboxilate-based superplasticizer (Sika ViscoCrete ${ }^{\circledR}$ 5720) was used. The superplasticizer quantities depend on the wt.\% of cement replaced, as well as the morphological characteristic of the functional particles. Ghafari et al. pointed out that cement paste composites containing 0.4 wt. $\% \mathrm{ZnO}$ nanoparticles (specific surface area of $54 \pm 20 \mathrm{~m}^{2} / \mathrm{g}$ ) or lower showed excellent workability retention compared to the reference mix and a poor workability retention was observed at higher dosage (Ghafari et al. [51]). Once the dosages have been prepared by both mixing methods, they are placed in a rotary mixer that contains the required water and the superplasticizer (following with a low-speed knead for 90 seconds). 


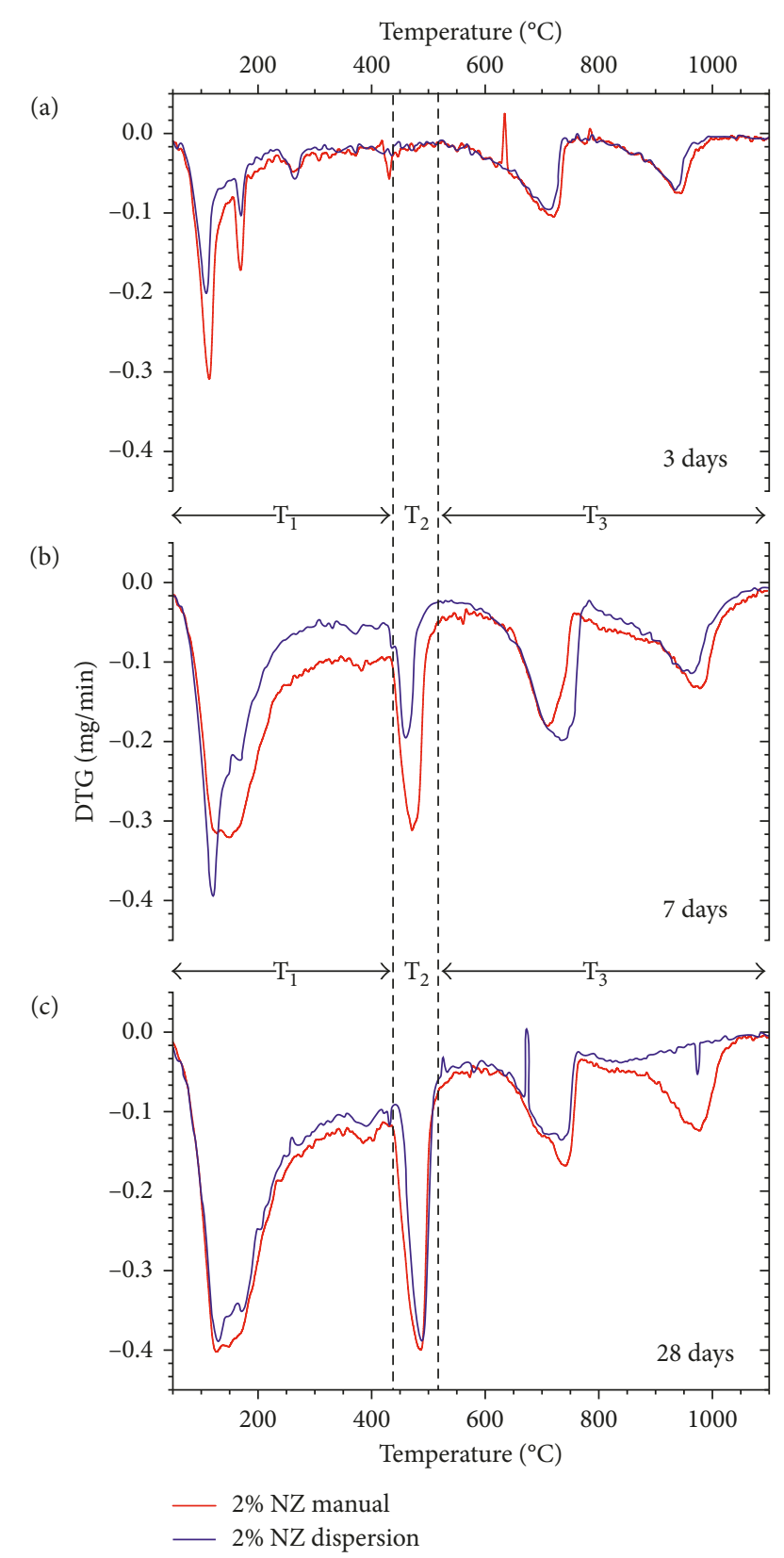

Figure 1: DTG-Ta analysis for cement paste with 2 wt.\% of nanozinc (NZ) for (a) 3, (b) 7, and (c) 28 days.

After 30 seconds of rest, the mixture was mixed again for 90 seconds at a low speed. After mixing, the cement pastes were shaped as a prismatic bar in molds and covered with a plastic bag and placed in a curing chamber with the temperature and humidity controlled $\left(20 \pm 2^{\circ} \mathrm{C}\right.$ and $>95 \%$, resp.). As zinc oxide is a cement hydration retarder, samples were demolded after 72 hours and cured in water inside the chamber. In order to stop the hydration of the samples at the ages analyzed, the cement paste was placed in vacuum for 30 minutes and then in acetone for two hours, following 24 hours in a stove at $60^{\circ} \mathrm{C}$. The sample was stored in a stove at $40^{\circ} \mathrm{C}$ until its structural and microstructural characterization had been obtained. Cement pastes were cured for one, two, three, seven, and twenty-eight days in water and characterized by means of DTA-TG, SEM, FTIR, and XRD.

2.3. Characterization of Cement Pastes with Additions. The differential thermal analysis and thermogravimetry (DTATG) of the cement pastes were performed by using LABSYS evo equipment provided by SETARAM Instrumentation, in the range of $25^{\circ} \mathrm{C}$ to $1100^{\circ} \mathrm{C}$ with a heating rate of $10^{\circ} / \mathrm{min}$ in $\mathrm{N}_{2}$ atmosphere in alumina crucibles. The cement pastes were microstructurally characterized by scanning electron microscopy (SEM) with a JEOL JSM 6335F microscope, and the energy dispersive spectroscopy (EDS) analysis was carried out with a detector provided by Oxford Instruments, the $\mathrm{X}-\mathrm{Max}^{\mathrm{N}}$ of $80 \mathrm{~mm}^{2}$ with a resolution between $127 \mathrm{eV}$ and $5.9 \mathrm{KeV}$. In addition, X-ray diffraction (XRD) was carried out by means of a powder diffractometer Bruker D8 ADVANCE with $\mathrm{Cu} \mathrm{K} \alpha$ radiation, with a high-speed detector (Lynxeye). The identification of the crystalline phases was done by comparison with the Joint Committee on Powder Diffraction Standards (JCPDS) guidelines. FTIR analysis of the cement pastes shaped in the $\mathrm{KBr}$ pellet method was performed by a PerkinElmer Spectrum 100 spectrophotometer from 400 to $4000 \mathrm{~cm}^{-1}$.

\section{Results and Discussion}

The thermogravimetric derivative (DTG) versus temperature plot represents the mass change rate with temperature $\left(T^{\mathrm{e}}\right)$ and allows a better resolution of the complex thermogravimetric curves. By quantifying the water related with the $\mathrm{CSH}$ gel and the portlandite phase $(\mathrm{CH})$, it is possible to analyze the hydration grade. The DTG versus $T^{\mathrm{e}}$ plot of cement pastes shows the following characteristic bands: first, the free water loss occurs approximately at $100^{\circ} \mathrm{C}$, then the interlayer water loss occurs at around $120^{\circ} \mathrm{C}$, and finally, from $140^{\circ} \mathrm{C}$ until $430^{\circ} \mathrm{C}$, the water of gel (water combined in the CSH gel, T1) loss occurs. The portlandite content is related with the water weight loss that takes place in the temperature range between $430^{\circ} \mathrm{C}$ and $515^{\circ} \mathrm{C}$ (labeled as T2). Due to the possible portlandite carbonation, it is necessary to adjust the portlandite quantity and include it in the temperature range where the carbonate loss takes place $\left(515^{\circ} \mathrm{C}-1100^{\circ} \mathrm{C}\right)$. Villain et al. [52] indicated that the calcium carbonate $\left(\mathrm{CaCO}_{3}\right)$ ensuing of the $\mathrm{CSH}$ carbonation dissociates in a lower temperature range than the $\mathrm{CaCO}_{3}$ ensuing of the portlandite carbonation allowing it to differentiate both carbonations thermally. The authors consider that the water contained in the carbonates is $40 \mathrm{wt} . \%$ of the total weight loss in this temperature range. The $40 \mathrm{wt} . \%$ weight loss in this temperature range $\left(515^{\circ} \mathrm{C}-1100^{\circ} \mathrm{C}\right)$ will be termed $\mathrm{T} 3$.

Figures 1(a)-1(c) and Table 1 show the plot of DTG versus temperature, such as mass losses in the temperature ranges previously examined (T1, T2, and $\mathrm{T} 3$, resp.) for cement pastes with a substitution of $2 \mathrm{wt} . \%$ of nano- $\mathrm{ZnO}$ (NZ), obtained by both mixing methods at cured ages of three, seven, and twenty-eight days, in comparison with a cement paste without addition as reference. In the DTG plot of three-day samples (Figure 1(a)), there appear peaks corresponding to weight loss of water consequence of 
TABLe 1: Water losses associated with different phases in cement pastes with 2 wt.\% of nanozinc (NZ).

\begin{tabular}{|c|c|c|c|c|c|c|c|c|c|}
\hline & \multicolumn{3}{|c|}{$2 \% \mathrm{NZ}$ manual mixing } & \multicolumn{3}{|c|}{$\begin{array}{c}2 \% \mathrm{NZ} \mathrm{low} \mathrm{shear} \mathrm{rate} \\
\text { dispersion }\end{array}$} & \multicolumn{3}{|c|}{$52.5 \mathrm{R}$} \\
\hline & $3 \mathrm{~d}$ & $7 \mathrm{~d}$ & $28 \mathrm{~d}$ & $3 \mathrm{~d}$ & $7 \mathrm{~d}$ & $28 \mathrm{~d}$ & $3 \mathrm{~d}$ & $7 \mathrm{~d}$ & $28 \mathrm{~d}$ \\
\hline $\mathrm{T} 1\left(140^{\circ} \mathrm{C}-430^{\circ} \mathrm{C}\right)$ wt.\% & 2.0 & 7.3 & 9.2 & 1.5 & 4.6 & 8.6 & 6.6 & 7.0 & 7.8 \\
\hline $\mathrm{T} 2\left(430^{\circ} \mathrm{C}-515^{\circ} \mathrm{C}\right)$ wt. $\%$ & 0.3 & 2.7 & 3.5 & 0.2 & 1.4 & 3.2 & 3.4 & 3.5 & 3.5 \\
\hline $\mathrm{T} 3\left(515^{\circ} \mathrm{C}-1100^{\circ} \mathrm{C}\right)$ wt. $\%$ & 1.3 & 3.0 & 2.7 & 1.2 & 2.9 & 1.8 & 2.6 & 2.8 & 2.6 \\
\hline Total combined water $(\mathrm{T} 1+\mathrm{T} 2+\mathrm{T} 3)$ wt. $\%$ & 3.6 & 13.0 & 15.4 & 2.9 & 8.9 & 13.6 & 12.6 & 13.3 & 13.9 \\
\hline Equivalent calcium $(\mathrm{T} 2+\mathrm{T} 3)$ wt. $\%$ & 1.6 & 5.7 & 6.2 & 1.4 & 4.3 & 5.0 & 6.0 & 6.3 & 6.1 \\
\hline CSH gel (T1) wt.\%/total portlandite (T2 + T3) wt.\% & 1.25 & 1.28 & 1.48 & 1.07 & 1.07 & 1.72 & 1.10 & 1.11 & 1.28 \\
\hline
\end{tabular}

hydration of tricalcium aluminates $\mathrm{C}_{3} \mathrm{~A}\left(170^{\circ} \mathrm{C}\right.$ and $\left.265^{\circ} \mathrm{C}\right)$ corresponding to the initial formation of hexagonal phases. Subsequently, these will be converted to a $\mathrm{C}_{3} \mathrm{AH}_{6}$ cubic phase according to the literature and weight loss of carbonates as consequence carbonation of the samples (Ramachandran et al. [53]). The DTG of hydrated calcium hydroxyzincate $\left(\mathrm{CaZn}_{2}(\mathrm{OH})_{6} \cdot 2 \mathrm{H}_{2} \mathrm{O}\right)$ synthesized (Mellado et al. [54]) shows three peaks, the first two overlapped in a temperature range between $140^{\circ} \mathrm{C}$ and $220^{\circ} \mathrm{C}$ corresponding to the two first stages' decomposition of $\mathrm{CaZn}_{2}(\mathrm{OH})_{6} \cdot 2 \mathrm{H}_{2} \mathrm{O}$. At the lowest temperature, the dehydration of $\mathrm{CaZn}_{2}(\mathrm{OH})_{6} \cdot 2 \mathrm{H}_{2} \mathrm{O}$ takes place, and between $160^{\circ} \mathrm{C}$ and $220^{\circ} \mathrm{C}$ in the DTG, a wide peak appears corresponding to the decomposition of $\mathrm{CaZn}_{2}(\mathrm{OH})_{6}$ in $\mathrm{ZnO}$ and $\mathrm{Ca}(\mathrm{OH})_{2}$. Finally, at temperature around $500^{\circ} \mathrm{C}$, the $\mathrm{Ca}(\mathrm{OH})_{2}$ decomposition takes place. In Portland cement samples with $0.1 \%$ of $\mathrm{Zn}(\mathrm{II})$, Mellado et al. indicated the presence of two peaks in DTG at 180 and between $270^{\circ} \mathrm{C}$ and $290^{\circ} \mathrm{C}$ corresponding to the decomposition of hydrated calcium hydroxyzincate $\mathrm{CaZn}_{2}(\mathrm{OH})_{6} \cdot 2 \mathrm{H}_{2} \mathrm{O}$ and hydrozincite $\mathrm{Zn}_{5}\left(\mathrm{CO}_{3}\right)_{2}(\mathrm{OH})_{6}$, respectively.

In Figures $1(\mathrm{a})-1(\mathrm{c})$, two peaks appear before $200^{\circ} \mathrm{C}$ and $300^{\circ} \mathrm{C}$, respectively, that could correspond to the decomposition of hydrated calcium hydroxyzincate $\left(\mathrm{CaZn}_{2}(\mathrm{OH})_{6} \cdot 2 \mathrm{H}_{2} \mathrm{O}\right)$ and hydrozincite according to Mellado et al. [54]. In Figure 1(a), these peaks can appear overlapping with the hydration of tricalcium aluminates and therefore have a greater intensity.

Figure 1(a) and Table 1 data indicate that the hydration of calcium silicates has not taken place at this age, confirming the hydration retarder behaviour of $\mathrm{ZnO}$ on cement pastes in agreement with Mellado et al. that confirmed the absence of portlandite decomposition in cement pastes containing $1 \%$ of $\mathrm{Zn}(\mathrm{II})$ at 3 days due to the delay in the setting of the cement. Pastes at seven days show that hydration is taking place according to Figure 1(b) and Table 1 to a greater extent for cement paste prepared by a manual mixing method since the water of the CSH gel combined with portlandite for manual mixing cement pastes is higher than that obtained by the low shear dispersion method. For 28 days (Figure 1(c)), the hydration process for cement pastes obtained by both mixing methods is very similar. Only small differences can be observed in regard to the total combined water, in particular, due to the water contained in carbonates (Table 1, T3). According to Villain et al. [52], calcium carbonate $\mathrm{CaCO}_{3}$ ensuing form the degradation of the CSH gel gives place to vaterite and/or aragonite whose dissociation takes place between $650^{\circ} \mathrm{C}$ and $800^{\circ} \mathrm{C}$ and $\mathrm{CaCO}_{3}$ calcite ensuing from portlandite $\mathrm{Ca}(\mathrm{OH})_{2}$ carbonation dissociated between $850^{\circ} \mathrm{C}$ and $1000^{\circ} \mathrm{C}$ according to Figures $1(\mathrm{a})-1(\mathrm{c})$. For 28 days, the water loss combined with portlandite indicates that about $24 \%$ of total loss is due to the portlandite, with the portlandite content for samples obtained by both mixing methods being about 14 wt.\%. The CSH gel-portlandite ratio is higher for samples with nanozinc oxide than for the reference cement paste at 28 days for both experimental methods of obtaining the cement pastes. This result is a consequence of a higher content of water (higher combined water) in the gel (T1), though this does not mean that there is more CSH gel since the portlandite content (equivalent calcium) for all the samples with and without nano- $\mathrm{ZnO}$ is similar. This higher water content for samples with nano- $\mathrm{ZnO}$ could be due to the water bound to zinc in the calcium hydroxyzincate, given that, in these samples, there is no silica and the pozzolanic reaction cannot take place to form a secondary $\mathrm{CSH}$ gel. The hydration process in the first ages is different for each cement paste with nanozinc oxide depending on its mixing method, although in both cases hydration is later, with it being higher for cement pastes obtained at low shear rate dispersion. $\mathrm{ZnO}$ is not involved in the hydration process in cement pastes prepared by this method in the first ages, and the water bonded is lower than that in pastes prepared by manual mixing. For 28 days, hydration is similar for cement pastes obtained by both mixing methods. Cement pastes obtained by the novel dispersion method show a higher $\mathrm{CSH}$ gel-to-portlandite ratio than the manual mixing ones, indicating a higher $\mathrm{Ca} / \mathrm{Si}$ ratio and denser $\mathrm{CSH}$ gels.

The $\mathrm{Ca} / \mathrm{Si}$ ratio in a CSH gel of cement pastes obtained by both mixing methods was determined by SEM-EDX analysis at a different point of the surface of each sample at the age of 28 days. The $\mathrm{Ca} / \mathrm{Si}$ ratio for both mixing methods was similar, with the values of 2.44 and 2.52 for manual and dispersing methods, respectively. These $\mathrm{Ca} / \mathrm{Si}$ ratios are slightly higher than those for $52.5 \mathrm{R}$ cement pastes with a $\mathrm{Ca} / \mathrm{Si}$ ratio of 2.28. Accordingly, the $\mathrm{ZnO}$ addition increases the $\mathrm{Ca} / \mathrm{Si}$ ratio in the $\mathrm{CSH}$ gel.

FTIR analysis for cement pastes with nano- $\mathrm{ZnO}$ additions (Figure 2) is in agreement with the DTA-TG characterization. At three days, the hydration of calcium silicates has not started, and only the hydration of the calcium aluminates can be observed in the cement pastes and the mixing methods studied. FTIR analysis identified alite (A) as unhydrated cement particles and an ettringite (E) phase, as a consequence of calcium aluminate hydration. The carbonate peaks as a consequence of paste carbonation and peaks corresponding to bending water or in capillaries are 


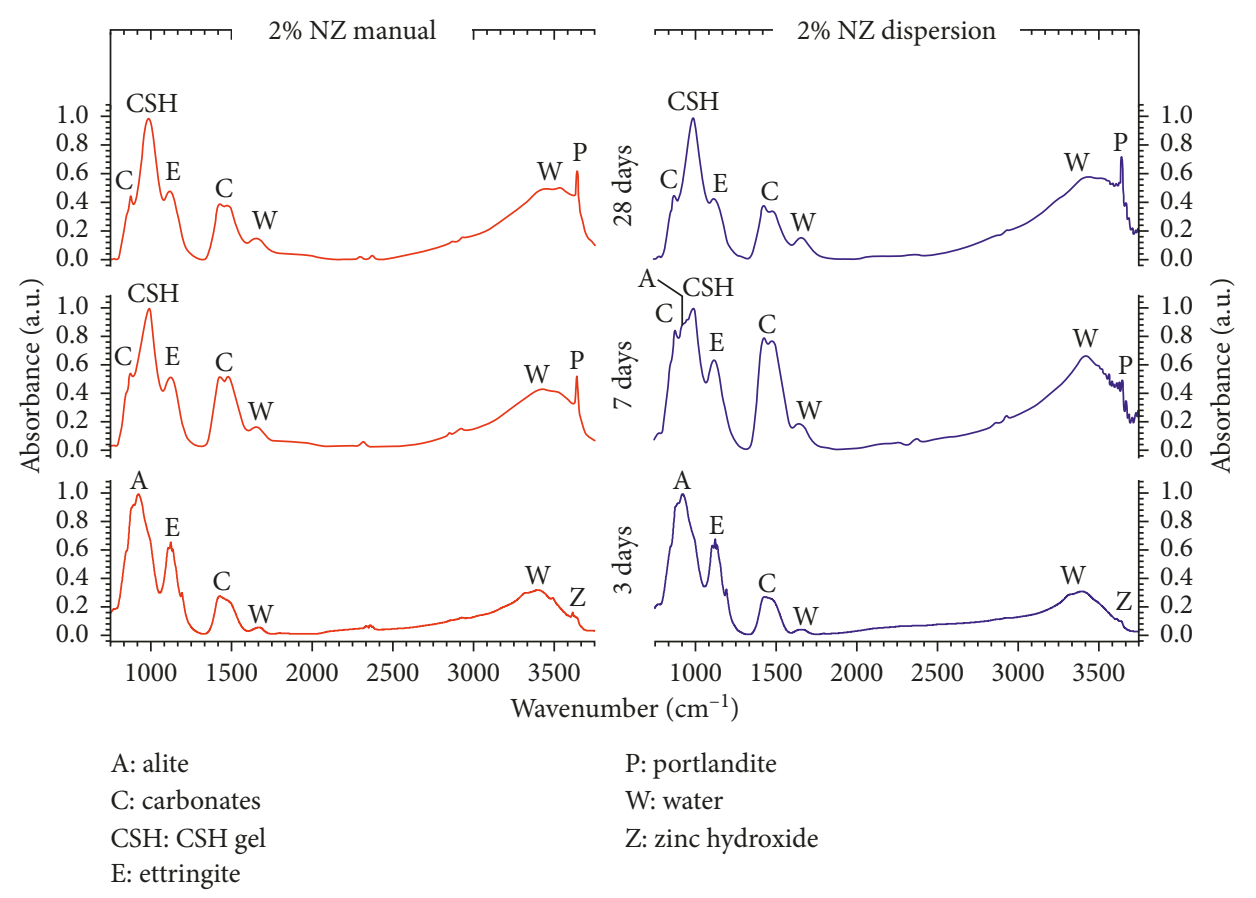

FIGURE 2: FTIR analysis for cement paste with 2 wt.\% of nanozinc (NZ).

identified too. The point to the presence at three days of the cement paste by mixing oxide of a weak peak at $3615 \mathrm{~cm}^{-1}$ that could be attributed to $\mathrm{OH}$ groups joined to $\mathrm{Zn}$ ions (zinc hydroxide) (Mollah et al. [55] and Trezza [56]). These results are in agreement with Arliguie, who pointed out that the formation of an amorphous layer of zinc hydroxide on the surface of anhydrous cement particles inhibits cement hydration (Arliguie and Grandet [31]). For cured cement pastes at seven days, there is agreement with the DTA-TG analysis, with the hydration of manual mixing cement pastes being almost complete since the displacement of the peak corresponding to the unhydrated alite phase from 920 to $985 \mathrm{~cm}^{-1}$ and corresponding to the $\mathrm{C}_{3} \mathrm{~S}$ hydration product (formation of the CSH gel) is clearly identified. In this sample, a sharp peak at $3645 \mathrm{~cm}^{-1}$ corresponding to the $\mathrm{O}-\mathrm{H}$ stretching of portlandite $\mathrm{Ca}(\mathrm{OH})_{2}$ formed together with the $\mathrm{CSH}$ gel in the hydration of calcium silicates is identified. For dispersed samples at seven days, portlandite identification is not possible, although the formation of the $\mathrm{CSH}$ gel takes place according to the incipient peak at $985 \mathrm{~cm}^{-1}$ such as a decrease in the alite phase, confirming the progress of hydration. In agreement with the literature (Vázquez Moreno [57]), the intensity of the band corresponding to ettringite decreases with its transformation in monosulfoaluminates. In this case, for pastes with NZ, this change takes place when the age increases from three to seven days. For 28 days, FTIR analysis would indicate a slightly greater advance of hydration of cement pastes obtained by a manual mixing method as the greater intensity of the portlandite and $\mathrm{CSH}$ gel peaks, together with alite, is not identified.

$\mathrm{X}$-ray diffraction characterization (Figure 3) is in agreement with DTA-TG and FTIR analyses for cement pastes with nanozinc oxide additions for both mixing methods. For samples at three days, calcium silicate hydration has not started (alite and belite identification), with there even being aluminates identified. For pastes at seven days, hydration is at a greater point of advance in cement pastes obtained by manual mixing than for low shear rate dispersion for seven days. At this age, manual mixing sample characterization shows that the peaks corresponding to the alite phase (A) have a lower intensity than those corresponding to low shear rate dispersion ones. For 28 days, according to XRD analysis, there are no hydration differences between cement pastes obtained by both mixing methods. At this age, by means of this characterization technique, it is possible to identify traces of unhydrated alite. It should be noted that it is possible to identify the crystalline calcium hydroxyzincate dihydrate $\mathrm{CaZn}_{2}(\mathrm{OH})_{6} \cdot 2 \mathrm{H}_{2} \mathrm{O}(\mathrm{CZ})$ phase at any cured age. The identification by the FTIR of the amorphous zinc hydroxide $\mathrm{Zn}(\mathrm{OH})_{2}$ phase at the earliest age (three days) and crystalline calcium hydroxyzincate dihydrate $\mathrm{CaZn}_{2}(\mathrm{OH})_{6} \cdot 2 \mathrm{H}_{2} \mathrm{O}(\mathrm{CZ})$ for all ages in XRD analysis would agree with the Arliguie and Grandet proposal [31] where these authors indicated that the delay in hydration is due to the precipitation of an amorphous $\mathrm{Zn}(\mathrm{OH})_{2}$ layer around the anhydrous $\mathrm{C}_{3} \mathrm{~S}$ grains which inhibits cement dissolution. When the hydration reaction starts again, the amorphous $\mathrm{Zn}(\mathrm{OH})_{2}$ layer transforms into a crystalline calcium hydroxyzincate $\mathrm{CaZn}_{2}(\mathrm{OH})_{6} \cdot 2 \mathrm{H}_{2} \mathrm{O}$ (CZ). In a recent published study, Andrade et al. studied cement pastes with zinc oxide addition for electric arc furnace dust (EAFD) recycling (Andrade Brehm et al. [58]). They proposed a model to explain hydration reactions of cement admixed with $\mathrm{ZnO}$. In this work, the authors identified the $\mathrm{CaZn}_{2}(\mathrm{OH})_{6} \cdot 2 \mathrm{H}_{2} \mathrm{O}(\mathrm{CZ})$ phase at two days and suggested the starting of the hydration reactions in these cement pastes with $\mathrm{ZnO}$ in agreement with Arliguie and stated that $\mathrm{Zn}(\mathrm{OH})_{2}$ is not the responsible phase of retardation of setting time since, according to the $\mathrm{pH}$ diagram at the $\mathrm{pH}$ of the cement pastes 


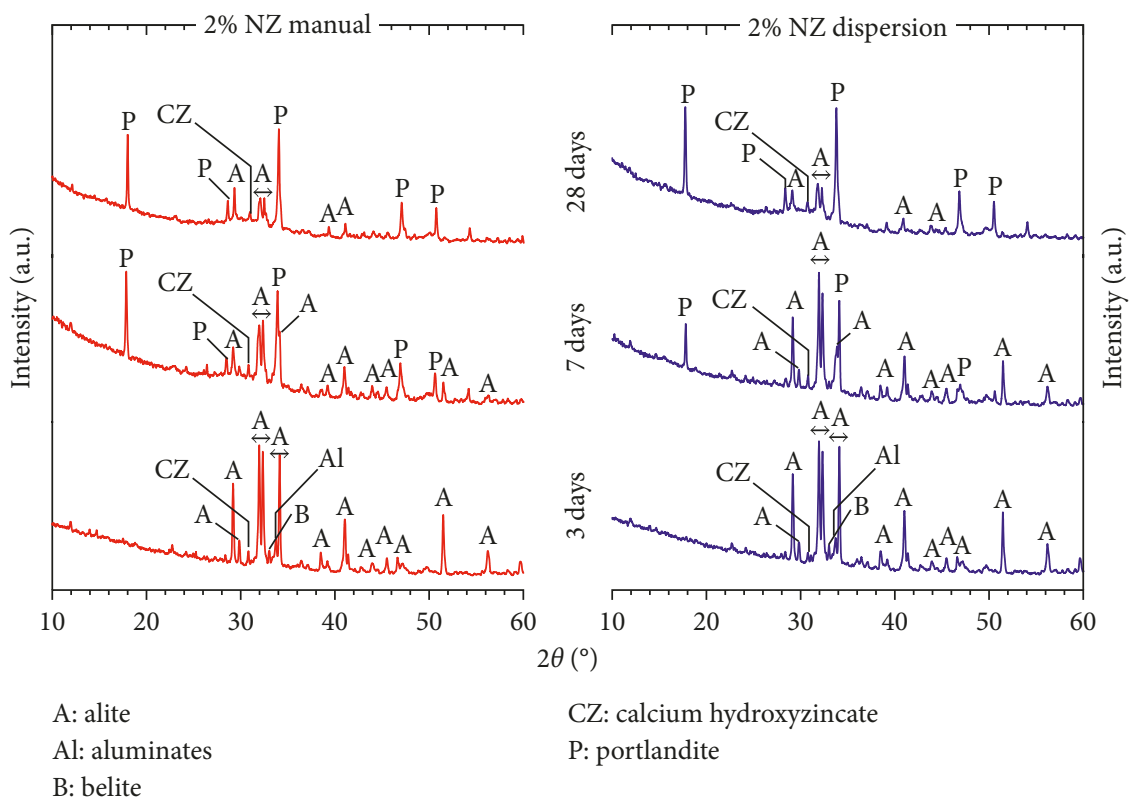

FIgURE 3: XRD characterization for cement paste with 2 wt.\% of nanozinc (NZ).

$(\approx 12)$, there would be a small amount of this phase. The most important result, regardless of the characterization technique, is that there are no significant differences in hydration of cement pastes at 28 days with a substitution of $2 \mathrm{wt} . \%$ of nano$\mathrm{ZnO}$ obtained by both mixing methods.

Figures 4(a)-4(c) and Table 2 show the DTG (mass change speed) versus temperature as mass loss from the TG data for the interest temperature ranges defined previously (T1, T2, and T3) and associated with water loss of a different nature for cement pastes with a cement substitution of 2 wt.\% nano- $\mathrm{ZnO}$ and 10 wt.\% microsilica (MS) obtained for both mixing methods at ages of three, seven, and twenty-eight days, respectively.

DTG analysis and water losses associated with different phases (Table 2) of three-day samples with $\mathrm{ZnO}$ and microsilica (Figure 4(a)) are close to the three-day pastes only with nanoparticles for both mixing methods. The hydration of calcium silicates has not taken place at this age. Pastes at seven days (Figure 4(b)) show that calcium silicate hydration has taken place for manual mixing samples but not so for low shear rate dispersion pastes. The total water combined with cement pastes prepared by low shear rate dispersion at seven days is similar to that at three days. Water loss that takes part in the CSH gel (T1) and water combined with portlandite (T2) are low compared with manual mixing pastes according to Table 2. The absence of the peaks corresponding to the water loss that takes part in the CSH gel (T1) and water combined with portlandite (T2) in DTG analysis confirms that the hydration of calcium silicates either has not started or is at an only slightly advanced at seven days for pastes prepared by the dispersion method. There are meaningful differences related to the quantities of water that are part of the $\mathrm{CSH}$ gel, as well as water combined with portlandite, that indicate a higher hydration of calcium silicate of manual mixing cement pastes. Pastes only with $\mathrm{ZnO}$ hydration at seven days have started in both mixing methods, although higher advanced points for pastes are obtained by manual mixing. In Figures 4(a)-4(c), two peaks appear before $200^{\circ} \mathrm{C}$ and $300^{\circ} \mathrm{C}$, respectively, that could correspond to the decomposition of hydrated calcium hydroxyzincate $\left(\mathrm{CaZn}_{2}(\mathrm{OH})_{6} \cdot 2 \mathrm{H}_{2} \mathrm{O}\right)$ and hydrozincite according to Mellado et al. [54]. In Figure 4(a), these peaks can appear overlapping with the hydration of tricalcium aluminates and therefore have a greater intensity.

At 28 days, the hydration process for cement pastes with $\mathrm{NZ}$ and MS obtained for both mixing methods is identical according to DTG analysis and associated water losses (Figure 4(c) and Table 2). At 28 days, the water loss combined with portlandite indicates that about $16 \mathrm{wt} . \%$. of total loss is due to portlandite and the portlandite content for samples obtained by both mixing methods being about $9 \%$ of total weight. This minor content, compared with pastes, is only with nanozinc and is a consequence of the pozzolanic reaction between portlandite and the microsilica.

Similar to Figures 1(a)-1(c), calcium carbonate $\mathrm{CaCO}_{3}$ dissociation ensuing form the degradation of the $\mathrm{CSH}$ gel takes place between $650^{\circ} \mathrm{C}$ and $800^{\circ} \mathrm{C}$ and $\mathrm{CaCO}_{3}$ calcite ensuing from portlandite $\mathrm{Ca}(\mathrm{OH})_{2}$ carbonation dissociated between $850^{\circ} \mathrm{C}$ and $1000^{\circ} \mathrm{C}$ according to Figures $4(\mathrm{a})-4(\mathrm{c})$.

The CSH gel-portlandite ratio is higher for samples with nanozinc oxide and microsilica than for the reference cement paste at 28 days for both experimental methods of obtaining the cement pastes, as occurred in the case of the cement pastes only with nanozinc oxide. Unlike cement pastes only with zinc oxide, this result is a consequence not only of the higher content of water (higher combined water) in the gel (T1) due to the water bound to zinc in calcium hydroxyzincate but also of the formation of the CSH gel because of the pozzolanic reaction due to microsilica addition. As a result of the pozzolanic reaction, the portlandite content (equivalent calcium) for the cement pastes with nano- $\mathrm{ZnO}$ regardless of the mixing method is similar and lower than that for reference pastes without $\mathrm{ZnO}$. As for cement pastes with only $\mathrm{ZnO}$, the 


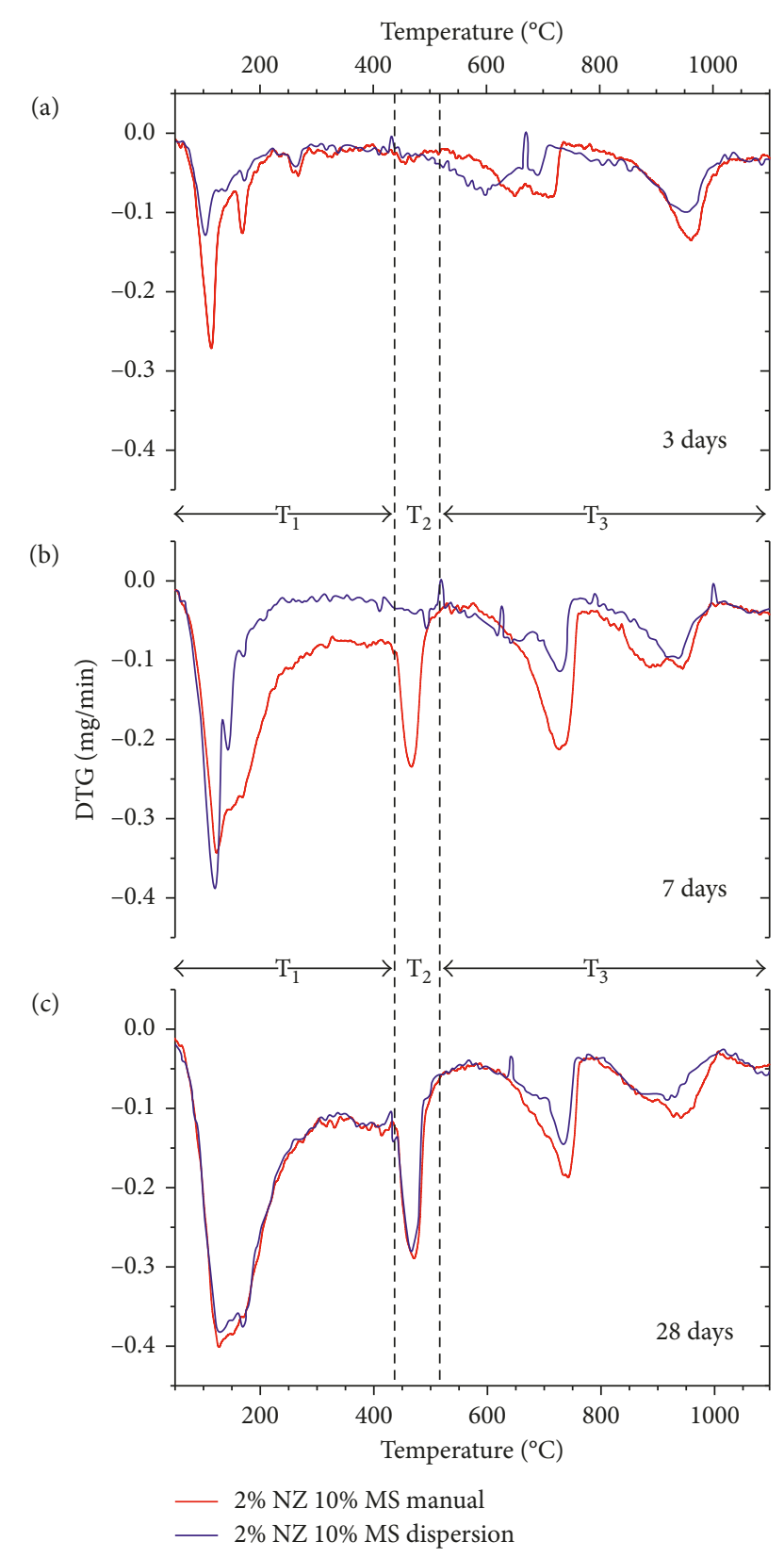

FIGURE 4: DTG-T ${ }^{\mathrm{a}}$ analysis for cement paste with $2 \mathrm{wt} . \%$ of nanozinc (NZ) + 10 wt.\% microsilica (MS) for (a) 3, (b) 7, and (c) 28 days.

hydration process in the first ages is different for each cement paste with nanozinc oxide and microsilica depending on its mixing method, although in both cases hydration is later, with this being higher for cement pastes obtained at low shear rate dispersion. $\mathrm{ZnO}$ does not occur in the hydration in cement pastes prepared by this method in the first ages, and the water bonded is lower than that in pastes prepared by manual mixing. At 28 days, hydration is similar for cement pastes obtained by both mixing methods. Cement pastes obtained by the novel dispersion method show a higher CSH gelportlandite ratio than the manual mixing ones, indicating a higher $\mathrm{Ca} / \mathrm{Si}$ ratio and therefore denser $\mathrm{CSH}$ gels.

The CSH gel-portlandite ratio is higher for samples with nanozinc oxide and microsilica than for the reference cement paste at 28 days for both experimental methods of obtaining the cement pastes, due in part to the water content in calcium hydroxyzincate and because it is not related to the $\mathrm{CSH}$ gel (there is also a formation of secondary CSH gel consequence of the pozzolanic reaction). This result would provide better mechanical properties for samples with nanozinc oxide and microsilica substitutions for both mixing methods compared with the reference pastes. The $\mathrm{CSH}$ gel-portlandite ratio for samples with zinc oxide and microsilica is higher than that for samples only with zinc oxide due to the pozzolanic reaction forming a secondary $\mathrm{CSH}$ gel.

The Ca/Si ratio in the CSH gel of cement pastes with NZ and MS obtained by SEM-EDX analysis at 28 days shows such a ratio for both mixing methods as similar, although slightly higher for manual mixing, with the values of 2.20 and 2.25 , respectively. The $\mathrm{Ca} / \mathrm{Si}$ ratio decreases with the addition of $\mathrm{SiO}_{2}$.

As the plot of DTG versus $T^{\mathrm{a}}$ of cement pastes that contain NZ and nanosilica NS is close to that of cement pastes that contain NZ and MS, it is not shown in this article. Table 3 shows the mass loss from the TG data for the interest temperature ranges defined previously (T1, T2, and T3) and associated with the water loss of different nature for cement pastes with NZ and NS for three, seven, and twenty-eight days, respectively.

At three days of hydration, cement pastes with $\mathrm{NZ}$ and NS obtained by both mixing methods, as for cement pastes with NZ and MS, the hydration of calcium silicates has either not taken place or at a little advanced point according to the gel water losses. Pastes at seven days show that calcium silicate hydration has taken place for manual mixing samples but not so for low shear rate dispersion pastes. The total water combined with the cement paste prepared by low shear rate dispersion at seven days is similar to that at three days, as shown in Table 3. According to this DTG analysis and the values shown in Table 3, the result would indicate that at seven days for manual mixing pastes, hydration is already advanced and for dispersing samples, it would be starting. According to findings in another study, nanosilica accelerated $\mathrm{C}_{3} \mathrm{~S}$ hydration [21]; however, in this study, the hydration retarder effect of $\mathrm{ZnO}$ prevailed. Water losses that took part in the CSH gel (T1) and combined with portlandite (T2) in the first ages (three and seven days) are similar for samples that do not contain silica or contain micro- or nanosilica. For 28 days, the hydration process for cement pastes obtained for both mixing methods is similar. Water loss that takes part in the CSH gel (T1) at 28 days for cement pastes with NS is higher than that for the MS ones, with this indicating that nanosilica produces a higher quantity of hydrated phase and showing agreement with the literature (Tobón et al. [59]).

It is important to note, in agreement with the literature, that nanosilica has a pozzolanic reactivity higher than microsilica and, that is, produces additional CSH gel (Land and Stephan [21]). According to Table 3, cement pastes with nanosilica for both mixing methods at 28 days show a higher water loss that takes part in the CSH gel (T1) than the water loss for samples with microsilica (Table 3 ) which correspond 
TABLE 2: Water losses associated with different phases in cement pastes with 2 wt.\% of nanozinc (NZ) + 10 wt.\% microsilica (MS).

\begin{tabular}{|c|c|c|c|c|c|c|c|c|c|}
\hline & \multicolumn{3}{|c|}{$\begin{array}{c}2 \% \mathrm{NZ}+10 \% \mathrm{MS} \\
\text { manual mixing (wt.\%) }\end{array}$} & \multicolumn{3}{|c|}{$\begin{array}{c}2 \% \mathrm{NZ}+10 \% \text { MS low } \\
\text { shear rate dispersion } \\
(\mathrm{wt} . \%)\end{array}$} & \multicolumn{3}{|c|}{$52.5 \mathrm{R}$} \\
\hline & $3 \mathrm{~d}$ & $7 \mathrm{~d}$ & $28 \mathrm{~d}$ & $3 \mathrm{~d}$ & $7 \mathrm{~d}$ & $28 \mathrm{~d}$ & $3 \mathrm{~d}$ & $7 \mathrm{~d}$ & $28 \mathrm{~d}$ \\
\hline $\mathrm{T} 1$ & 1.8 & 6.1 & 8.8 & 1.3 & 2.0 & 9.0 & 6.6 & 7.0 & 7.8 \\
\hline $\mathrm{T} 2$ & 0.4 & 1.8 & 2.5 & 0.4 & 0.5 & 2.5 & 3.4 & 3.5 & 3.5 \\
\hline T3 & 2.1 & 3.0 & 3.0 & 2.0 & 2.2 & 2.6 & 2.6 & 2.8 & 2.6 \\
\hline Total combined water $(\mathrm{T} 1+\mathrm{T} 2+\mathrm{T} 3)$ wt. $\%$ & 4.3 & 10.9 & 14.3 & 3.7 & 4.7 & 14.1 & 12.6 & 13.3 & 13.9 \\
\hline Equivalent calcium $(\mathrm{T} 2+\mathrm{T} 3)$ wt. $\%$ & 2.5 & 4.8 & 5.5 & 2.4 & 2.7 & 5.1 & 6.0 & 6.3 & 6.1 \\
\hline CSH gel (T1) wt.\%/total portlandite (T2 + T3) wt.\% & 0.72 & 1.27 & 1.60 & 0.54 & 0.74 & 1.76 & 1.10 & 1.11 & 1.28 \\
\hline
\end{tabular}

TABLE 3: Water losses associated with different phases in cement pastes with 2 wt.\% of nanozinc (NZ) + 10 wt.\% nanosilica (NS).

\begin{tabular}{|c|c|c|c|c|c|c|c|c|c|}
\hline & \multicolumn{3}{|c|}{$\begin{array}{c}2 \% \mathrm{NZ}+10 \% \mathrm{NS} \\
\text { manual mixing (wt.\%) }\end{array}$} & \multicolumn{3}{|c|}{$\begin{array}{c}2 \% \mathrm{NZ}+10 \% \mathrm{NS} \text { low } \\
\text { shear rate dispersion } \\
(\text { wt. } \%)\end{array}$} & \multicolumn{3}{|c|}{$52.5 \mathrm{R}$} \\
\hline & $3 \mathrm{~d}$ & $7 \mathrm{~d}$ & $28 \mathrm{~d}$ & $7 \mathrm{~d}$ & $28 \mathrm{~d}$ & $28 \mathrm{~d}$ & $3 \mathrm{~d}$ & $7 \mathrm{~d}$ & $28 \mathrm{~d}$ \\
\hline $\mathrm{T} 1$ & 3.0 & 8.0 & 11.2 & 2.7 & 3.8 & 10.5 & 6.6 & 7.0 & 7.8 \\
\hline $\mathrm{T} 2$ & 0.8 & 1.7 & 2.0 & 0.7 & 1.0 & 2.1 & 3.4 & 3.5 & 3.5 \\
\hline T3 & 1.3 & 3.0 & 2.8 & 0.9 & 1.9 & 3.0 & 2.6 & 2.8 & 2.6 \\
\hline Total combined water & 5.1 & 12.7 & 16.0 & 4.3 & 6.7 & 15.6 & 12.6 & 13.3 & 13.9 \\
\hline Equivalent calcium (T2+ T3) wt.\% & 2.1 & 4.7 & 4.8 & 1.6 & 2.9 & 5.1 & 6.0 & 6.3 & 6.1 \\
\hline CSH gel (T1) wt.\%/total portlandite (T2 + T3) wt.\% & 1.43 & 1.70 & 2.33 & 1.68 & 1.31 & 2.06 & 1.10 & 1.11 & 1.28 \\
\hline
\end{tabular}

with a higher CSH gel formation. A higher CSH gel formation is important since this phase is responsible for the mechanical properties, adherence, and contribution to the durability of cement-based materials. For 28 days, water loss combined with portlandite indicates that about 9 wt. $\%$ of total loss is due to the portlandite (the portlandite content for samples obtained by both mixing methods is about a $6 \%$ total weight). This minor portlandite content, compared with pastes only with nanozinc, is a consequence of the pozzolanic reaction. According to the literature, nanosilica promotes the pozzolanic reaction since the pozzolanic reaction is proportional to the specific surface available for the reaction. Micro- and nanosilica, in this work, have a surface area of 28 and $150 \mathrm{~m}^{2} / \mathrm{g}$, respectively (Jo et al. [60]). For samples with nanozinc oxide and with or without microsilica, the CSH gelportlandite ratio is higher for samples with nanozinc oxide and nanosilica than for the reference cement paste at 28 days regardless of the mixing method. The explanation is the same as that for samples with microsilica. Cement pastes with nanosilica for both mixing methods show the highest $\mathrm{CSH}$ gel-portlandite ratios as a consequence of a higher extent of the pozzolanic reaction since such a reaction is proportional to the surface area of silica and is one order of magnitude higher for nanosilica than for microsilica. In all cement paste mixtures, the hydration process at early ages is different for each mixing method; although in both types, the hydration process is retarded (such an effect is greater for cement pastes obtained by low shear rate dispersion). $\mathrm{ZnO}$ is not involved in the hydration in cement pastes prepared by this method in the first ages, and the water bonded is lower than that in pastes prepared by manual mixing. At 28 days, hydration is similar for cement pastes obtained by both mixing methods.

The $\mathrm{Ca} / \mathrm{Si}$ ratio in a $\mathrm{CSH}$ gel of cement pastes obtained by SEM-EDX analysis at the age of 28 days shows such a ratio for both mixing methods as similar with values of 1.95 and 1.78 for manual and dispersion mixing methods, respectively. The addition of silica decreases the $\mathrm{Ca} / \mathrm{Si}$ ratio in the CSH gel, with this decrease being more meaningful when nanosilica (NS) is added.

FTIR analysis (Figure 5) for cement pastes with NZ and MS obtained by both mixing methods shows at three days that the cement paste by mixing oxide could be forecast as the peak corresponding to $\mathrm{OH}^{-}$groups joined to $\mathrm{Zn}$ ions (zinc hydroxide), although in this case it is even weaker. The hydration behaviour is similar to that identified in cement pastes only with NZ: calcium silicate hydration has not started and the hydration of the calcium aluminates has only happened, according to the identification of alite (A) and ettringite (E). Pastes at seven days show that calcium silicate hydration has taken place for manual mixing samples but not so in the case of low shear rate dispersion pastes, in agreement with DTA-TG analysis. As can be observed in Figure 5, in manual mixing samples, the peak corresponding to the unhydrated alite phase has moved from 920 to $995 \mathrm{~cm}^{-1}$, corresponding to the $\mathrm{C}_{3} \mathrm{~S}$ hydration product (formation of the $\mathrm{CSH}$ gel) in addition to the portlandite phase. The hydration advance is higher for cement pastes prepared by a manual mixing method than for low-shear one. This is illustrated by the displacement of the peak corresponding to the $\mathrm{CSH}$ gel formation and also by a weak peak identified at $3645 \mathrm{~cm}^{-1}$ corresponding to the $\mathrm{O}-\mathrm{H}$ stretching of portlandite, formed together with the CSH gel in the hydration of calcium silicates. For cured cement pastes at 28 days, FTIR analysis shows an identical hydration of cement pastes obtained by both mixing methods. When the hydration age is 28 days, there is a meaningful decrease in the peak corresponding to the ettringite phase regardless of the mixing method used in agreement with the literature 


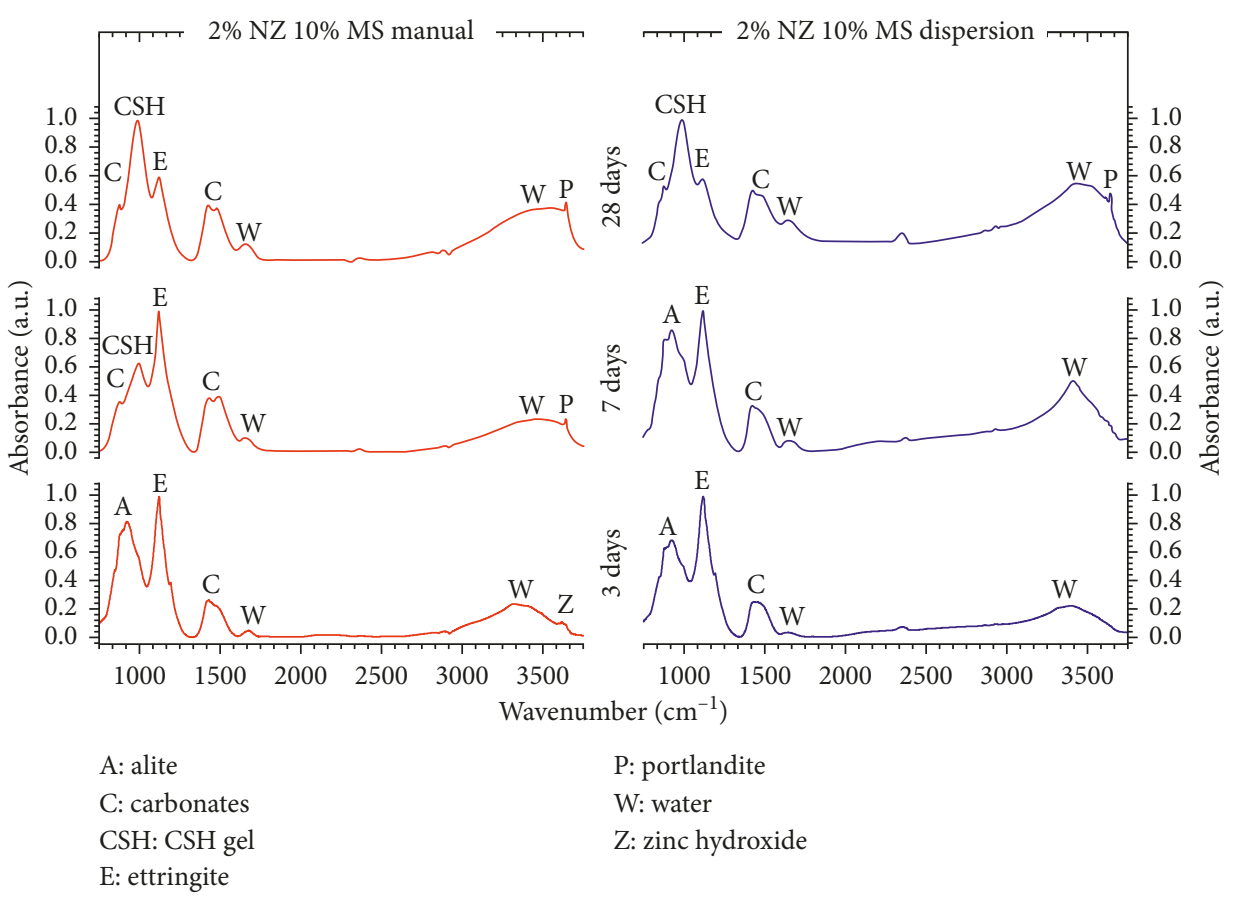

FIGURE 5: FTIR analysis for cement paste with 2 wt.\% of nanozinc (NZ) + 10 wt.\% microsilica (MS).

[57]. The intensity of the band corresponding to ettringite decreases as its transformation in monosulfoaluminates occurs. The only exceptions are cement pastes with only NZ as an addition, in which this change takes place when the age increases from three to seven days. It is important to note that the peak corresponding to portlandite $\left(3645 \mathrm{~cm}^{-1}\right)$ in samples with microsilica (seven and 28 days) shows a significantly lower intensity than for samples without silica due to portlandite reacting with silica in the presence of water to form a secondary CSH gel according to the following equation given by Neville and Brooks [61]:

$$
\mathrm{Ca}(\mathrm{OH})_{2}+\mathrm{SiO}_{2}+\mathrm{H}_{2} \mathrm{O} \rightarrow \mathrm{CSH} \text { gel. }
$$

Although the pozzolanic reaction does not lead to a higher water loss T1, if the values provided in Tables 1 and 2 are compared, where in samples only with $\mathrm{ZnO}$, the pozzolanic reaction cannot take place. Secondary CSH gels show lower $\mathrm{Ca} / \mathrm{Si}$ ratios, in accordance with the literature (Al-Dulaijan et al. [62]).

FTIR analysis for cement pastes with NZ and NS obtained by both mixing methods is similar to cement pastes that contain NZ and MS. For this reason, this is not shown in the article.

At three days, in all cement pastes obtained by both mixing methods, it is possible to observe calcium silicates (alite) and ettringite but not CSH gels. Therefore, the hydration process has been delayed by $\mathrm{ZnO}$. Pastes at seven days show that calcium silicate hydration takes place for manual mixing samples but not so for low shear rate dispersion pastes in agreement with DTG-T ${ }^{\mathrm{a}}$ analysis since for manual mixing samples the displacement of the peak corresponding to the unhydrated alite phase from 920 to $995 \mathrm{~cm}^{-1}$ corresponding to the $\mathrm{C}_{3} \mathrm{~S}$ hydration product (formation of $\mathrm{CSH}$ gel) has taken place. For cured cement pastes at 28 days, FTIR analysis shows an identical hydration of cement pastes obtained by both mixing methods. When the hydration age is at 28 days, there is a meaningful decrease in the peak corresponding to ettringite phase regardless of the mixing method used to obtain the cement pastes. It is important to note that the peak corresponding to portlandite $\left(3645 \mathrm{~cm}^{-1}\right)$ is not identified for any of the samples, as a consequence of a further extension of the pozzolanic reaction according to its higher surface area.

X-ray diffraction characterization (Figure 6) for cement pastes with NZ and MS shows agreement with DTA-TG analysis and FTIR in that hydration at three days is delayed for both mixing methods since only unhydrated phases are identified (calcium silicates and aluminates) in addition to calcium hydrozincite. At seven days, hydration is at a more advanced point in cement pastes obtained by manual mixing than for low shear rate dispersion. At this cured age, manual mixing sample characterization shows peaks corresponding to the portlandite phase $(\mathrm{P})$, unlike dispersing samples in which such a phase is not identified. For pastes obtained by dispersion, as the XRD pattern for ages three and seven days is identical, hydration is delayed. At 28 days, according to $\mathrm{XRD}$ analysis, there are no hydration differences between cement pastes obtained by both mixing methods. It should be noted that it is possible to identify the crystalline calcium hydroxyzincate dihydrate $\mathrm{CaZn}_{2}(\mathrm{OH})_{6} \cdot 2 \mathrm{H}_{2} \mathrm{O}(\mathrm{CZ})$ phase to any cured age for both pastes as in the pastes only with $\mathrm{ZnO}$. As in the case of the pastes only with $\mathrm{ZnO}$, given that an alite phase in cement pastes at ages of 28 days is identified, there are unhydrated cement particles.

$\mathrm{X}$-ray diffraction characterization for cement pastes with NZ and NS is identical to cement pastes with NZ and MS (Figure 6). At three days, hydration is delayed for both mixing methods, with unhydrated phases (calcium silicates 

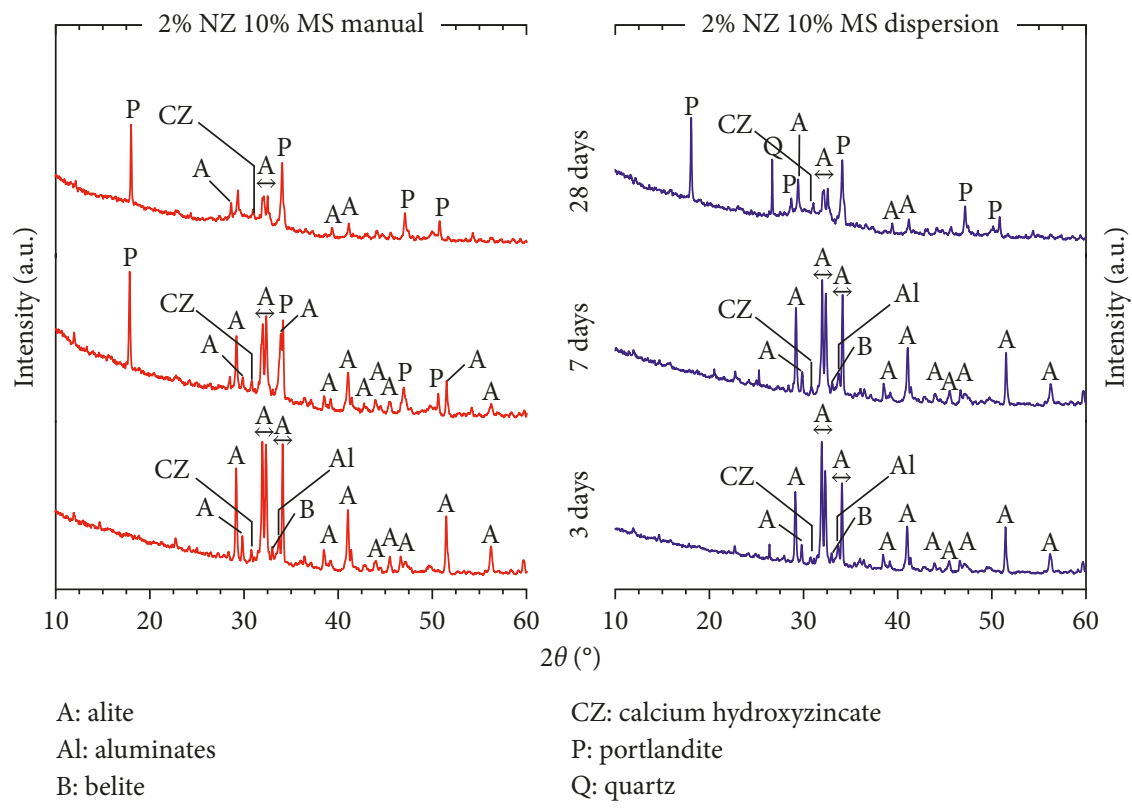

FIgURE 6: XRD characterization for cement paste with 2 wt.\% of nanozinc (NZ) + 10 wt.\% microsilica (MS).

and aluminates) being identified. At seven days, hydration is at a more advanced point in cement pastes obtained by manual mixing than for low shear rate dispersion. The portlandite phase only can be observed in pastes obtained by manual mixing. At 28 days, hydration for cement pastes obtained by both mixing methods is identical. It should be noted that it is possible to identify the crystalline calcium hydroxyzincate dihydrate $\mathrm{CaZn}_{2}(\mathrm{OH})_{6} \cdot 2 \mathrm{H}_{2} \mathrm{O}(\mathrm{CZ})$ phase to any cured age for both pastes, as in the pastes only with $\mathrm{ZnO}$ or with $\mathrm{ZnO}$ and microsilica. As in the case of other pastes, a small quantity of alite in cement pastes for both mixing methods at ages of 28 days is identified, indicating that there are unhydrated cement particles as a consequence of the hydration relay by the $\mathrm{ZnO}$ addition. By means of XRD diffraction, it is not possible to confirm the greatest extent of the pozzolanic reaction for pastes with NS than for MS (T2 values in Tables 2 and 3 and Figure 5) according to the intensity of the peak associated to the portlandite phase.

\section{Conclusions}

In this work, cement pastes with simultaneous functional additions (micro- and nanosilica and nanozinc oxide) have been prepared by means of two different mixing methods: a common manual mixing method and a novel low shear rate dispersion method. It highlights the viability of using a new dispersion method based on a low shear mixing to prepare cement pastes with nanometric simultaneous functional additions and limit exposure to the nanoparticles in order to avoid health risks.

At earliest age, hydration for both mixing methods has not started and it is identified by the amorphous zinc hydroxide phase, responsible for the hydration inhibition. When hydration is restarted, it is identified by the crystalline calcium hydroxyzincate phase in cement pastes prepared by both methods. The delay in hydration is higher for cement pastes obtained by low shear rate dispersion than with manual mixing. Nevertheless, at 28 days, hydration is similar for cement pastes obtained by both mixing methods.

In all the cement pastes with additions, the CSH gelportlandite ratio is higher than that for the reference cement paste without additions at 28 days regardless of the mixing method, with cement pastes with nanozinc oxide and nanosilica reaching the highest ratio value. This result is a consequence of the higher content of water (higher combined water) in the gel (T1) due to the water bound to zinc in calcium hydroxyzincate for cement pastes with nano$\mathrm{ZnO}$. In addition, the formation of a secondary $\mathrm{CSH}$ gel due to the pozzolanic reaction is greater for cement pastes with nanosilica because of its higher surface area.

The most important result obtained in agreement with the similar hydration behaviour of the different cement pastes prepared by both mixing methods is associated with the feasibility of using the novel low energy dry dispersion method to prepare cement pastes with simultaneous nanometric functional additions avoiding the exposure to the nanoparticles and therefore minimizing health risks.

\section{Conflicts of Interest}

The authors declare that there are no conflicts of interest regarding the publication of this paper.

\section{Acknowledgments}

This work was supported by the Spanish Ministry of Economy and Competitiveness through the Project MAT2017-86450-C4-1-R and Spanish National Research Council under Project NANOMIND 201560E068. F. Rubio-Marcos is also indebted to MINECO for a "Ramón y Cajal" contract (Ref. no. RyC-2015-18628), which is cofinanced by the European Social Fund. 


\section{References}

[1] L. Yang, A. Hakki, F. Wang, and D. E. Macphee, "Photocatalyst efficiencies in concrete technology: the effect of photocatalyst placement," Applied Catalysis B: Environmental, vol. 222, pp. 200-208, 2018.

[2] J. Chen, S.-c. Kou, and C.-s. Poon, "Photocatalytic cementbased materials: comparison of nitrogen oxides and toluene removal potentials and evaluation of self cleaning performance," Building and Environment, vol. 46, no. 9, pp. 18271833, 2011.

[3] P. Sikora, A. Augustyniak, K. Cendrowski et al., "Characterization of mechanical and bactericidal properties of cement mortars containing waste glass aggregate and nanomaterials," Materials, vol. 9, no. 8, p. 701, 2016.

[4] P. Sikora, K. Cendrowski, A. Markowska-Szczupak, E. Horszczaruk, and E. Mijowska, "The effects of silica/titania nanocomposite on the mechanical and bactericidal properties of cement mortars," Construction and Building Materials, vol. 150, no. 309, pp. 738-746, 2017.

[5] F. Tittarelli, "Oxygen diffusion through hydrophobic cementbased materials," Cement and Concrete Research, vol. 39, no. 10, pp. 924-928, 2009.

[6] C. Nunes and Z. Slizkova, "Hydrophobic lime based mortars with linseed oil: characterization and durability assessment," Cement and Concrete Research, vol. 61-62, pp. 28-39, 2014.

[7] W. De Muynck, N. De Belie, and W. Verstraete, "Antimicrobial mortar surfaces for the improvement of hygienic conditions," Journal of Applied Microbiology, vol. 108, no. 1, pp. $62-72,2009$.

[8] N. León, J. Massana, F. Alonso, A. Moragues, and E. SanchezEspinosa, "Effect of nano- $\mathrm{SiO}_{2}$ and nano- $\mathrm{Al}_{2} \mathrm{O}_{3}$ on cement mortars for use in agriculture and livestock production," Biosystems Engineering, vol. 123, no. 1, pp. 1-11, 2014.

[9] E. Mohseni, B. Mehdizaded, J. Yang, and M. Ali Yazdi, "Singel and combined effects of nano- $\mathrm{SiO}_{2}$, nano- $\mathrm{Al}_{2} \mathrm{O}_{3}$ and nano$\mathrm{TiO}_{2}$ on the mechanical, rheological and durability properties of self-compacting mortars containing fly ash," Construction and Building Materials, vol. 84, pp. 331-340, 2015.

[10] V. Vishwakarma, S. Sekhar Samal, and N. Manoharan, "Safety and risk associated with nanoparticles. A review," Journal of Minerals and Materials Characterization and Engineering, vol. 9, no. 5, pp. 455-459, 2010.

[11] M. A. Albrecht, C. W Evans, and C. L Raston, "Green chemistry and the health implications of nanoparticles," Green Chemistry, vol. 8, no. 5, pp. 417-432, 2006.

[12] N. C. Mueller and B. Nowack, "Exposure modeling of engineered nanoparticles in the environment," Environmental Science and Technology, vol. 42, no. 12, pp. 4447-4453, 2008.

[13] S. Haruehansapong, T. Pulngern, and S. Chucheepsakul, "Effect of the particle size of nanosilica on the compressive strength and the optimum replacement content of cement mortar containing nano- $\mathrm{SiO}_{2}$," Construction and Building Materials, vol. 50, pp. 471-477, 2014.

[14] L. Senff, J. A. Labrincha, V. M. Ferreira, D. Hotza, and W. Repette, "Effect of nano-silica on rheology and fresh properties of cement pastes and mortars," Construction and Building Materials, vol. 23, no. 7, pp. 2487-2491, 2009.

[15] J.-X. Lu and C.-S. Poon, "Improvement of early-age properties for glass-cement mortar by adding nanosilica," Cement and Concrete Composites, vol. 89, pp. 18-30, 2018.

[16] J. Massana, E. Reyes, J. Bernal, N. León, and E. SanchezEspinosa, "Influence of nano and micro-silica additions on the durability of a high performance self-compacting concrete,"
Construction and Building Materials, vol. 165, pp. 93-103, 2018.

[17] A. A. Ramezanianpour and M. A. Moeini, "Mechanical and durability properties of alkali activated slag coating mortars containing nanosilica and silica fume," Construction and Building Materials, vol. 163, no. 28, pp. 611-621, 2018.

[18] H. Cheng-yi and R. F. Feldman, "Hydration reactions in Portland cement-silica fume blends," Cement and Concrete Research, vol. 15, no. 4, pp. 585-592, 1985.

[19] J. A. Larbi, A. L. A. Fraay, and J. M. Bijen, "The chemistry of the pore fluid of silica fume-blended cement systems," Cement and Concrete Research, vol. 20, no. 4, pp. 506-516, 1990.

[20] J. J. Thomas, H. M. Jennings, and J. J. Chen, "Influence of nucleation seeding on the hydration mechanism of tricalcium silicate and cement," Journal of Physical Chemistry C, vol. 113, no. 11, p. 4237, 2009.

[21] G. Land and D. Stephan, "The influence of nano-silica on the hydration of ordinary Portland cement," Journal of Materials Science, vol. 47, no. 2, pp. 1011-1017, 2012.

[22] A. Moezzi, A. M. McDonagh, and M. B. Cortie, "Zinc oxide particles: synthesis, properties and applications," Chemical Engineering Journal, vol. 185-186, pp. 1-22, 2012.

[23] R. K. Sendi, "Effects of different compositions from magnetic and nonmagnetic dopands on structural and electrical properties of $\mathrm{ZnO}$ nanoparticles-based varistor ceramics," Solid State Sciences, vol. 77, pp. 54-61, 2018.

[24] D. Xu, K. Song, Y. Li, L. Jiao, and J. Song, " $\mathrm{Sc}_{2} \mathrm{O}_{3}$ doped $\mathrm{Bi}_{2} \mathrm{O}_{3}$ $\mathrm{ZnO}$ thin film varistors prepared by sol-gel method," Journal of Alloys and Compounds, vol. 746, pp. 314-319, 2018.

[25] M. Kahouli, N. Toursi, H. Guermazi, and S. Guermazi, "Enhanced structural and optical properties of $\mathrm{ZnO}$ nanopowder with tailored visible luminescence as a function of sodium hydroxide to zinc sulfate mass ratio," Advanced Powder Technology, vol. 29, no. 2, pp. 325-332, 2018.

[26] A. M. Hussein, A. V. Lefanova, R. T. Koodali, B. A. Logue, and R. V. Shende, "Interconnected $\mathrm{ZrO}_{2}$ doped $\mathrm{ZnO} / \mathrm{TiO}_{2}$ network photoanode for dye-sensitized solar cells," Energy Reports, vol. 4, pp. 56-64, 2018.

[27] T. V. Torchynska, B. El Filali, G. Polupan, A. L Diaz Cano, and I. Ballardo, "Luminescence, structure and aging c-axisoriented silver doped $\mathrm{ZnO}$ nanocrystalline films," Materials Science in Semiconductor Processing, vol. 79, no. 1, pp. 99-106, 2018.

[28] C. Klingshirn, "ZnO: from basics towards applications," Physica Status Solidi B, vol. 244, no. 9, pp. 3027-3073, 2007.

[29] V. S. Ramachandran, Handbook of Thermal Analysis of Construction Materials, Noyes Publications, New York, NY, USA, 2002.

[30] D. Nivethitha and S. Dharmar, "Effect if zinc oxide nanoparticle on strength of cement mortar," International Journal of Scientific Engineering and Technology, vol. 3, no. 5, pp. 123-127, 2016.

[31] G. Arliguie and J. Grandet, "Influence de la composition d'un ciment Portland sur son hydratation en presence de zinc," Cement and Concrete Research, vol. 20, no. 4, pp. 517-524, 1990.

[32] M. Yousuf, A. Mollah, T. R. Hess, Y. N. Tsai, and D. L. Cocke, "An FTIR and XPS investigations of the effects of carbonation on the solidification/stabilization of cement based systemsPortland Type V with zinc," Cement and Concrete Research, vol. 29, pp. 55-61, 1999.

[33] D. L. Cocke, M. Y. A. Mollah, T. R. Hess, and T. C. Lin, "In aqueous chemistry and geochemistry of oxides, oxyhydroxides and related materials," Materials Research Society, vol. 432, pp. 63-68, 1997. 
[34] C. A. Johnson and M. Kersten, "Solubility of $\mathrm{Zn}$ (II) in association with calcium silicate hydrates in alkaline solutions," Environmental Science and Technology, vol. 33, no. 13, pp. 2296-2298, 1999.

[35] W. Lieber and J. Gebauer, "Einbau von zink in calciumsilikathydrate," Zem.-Kalk-Gips, vol. 22, pp. 295-303, 1969.

[36] F. F. Ataie, M. C. G. Juenger, S. C. Taylor-Lange, and K. A. Riding, "Comparison of the retarding mechanisms of zinc oxide and sucrose on cement hydration and interactions with supplementary cementitious materials," Cement and Concrete Research, vol. 72, pp. 128-136, 2015.

[37] A. Stumm, K. Garbev, G. Beuchle et al., "Incorporation of zinc into calcium silicates hydrates, part I," Cement and Concrete Research, vol. 35, no. 9, pp. 1665-1675, 2005.

[38] S. K. Ouki and C. D. Hills, "Microstructure of Portland cement pastes containing metal nitrate salts," Waste Management, vol. 22, no. 2, pp. 147-151, 2002.

[39] F. Ziegler, A. M. Scheidegger, C. A. Johnson, R. Dahn, and E. Wieland, "Sorption mechanism of zinc to calcium silicate hydrate: $\mathrm{x}$-ray absorption fine structure (XAFS) investigation," Environmental Science and Technology, vol. 35, no. 7, pp. 15501555, 2001.

[40] F. Ziegler and C. A. Johnson, "The solubility of calcium zincate $\left(\mathrm{CaZn}_{2}(\mathrm{OH})_{6} \cdot 2 \mathrm{H}_{2} \mathrm{O}\right)$," Cement and Concrete Research, vol. 31, no. 9, pp. 1327-1332, 2001.

[41] F. Tittarelli and T. Bellezze, "Investigation of the major reduction reaction occurring during the passivation of galvanized steels rebars," Corrosion Science, vol. 52, no. 3, pp. 978-983, 2010.

[42] Y. Xie, Y. He, P. L. Irwin, T. Jin, and X. Shi, "Antibacterial activity and mechanism of action of zinc oxide nanoparticles against Campylobacter jejuni," Applied and Environmental Microbiology, vol. 77, no. 7, pp. 2325-2331, 2011.

[43] A. Sirelkhatim, S. Mahmud, A. Seeni et al., "Review on zinc oxide nanoparticles. Antibacterial activity and toxicity mechanism," Nano-Micro Letters, vol. 7, no. 3, pp. 219-242, 2015.

[44] N. Madhusudhana, K. Yogendra, K. Mahadevan, and S. Naik, "Photocatalytic degradation of coralene dark red $2 \mathrm{~B}$ azo dye using calcium zincate nanoparticles in presence of natural sunlight: an aid to environmental remediation," International Journal of Chemical Engineering and Applications, vol. 2, no. 4, pp. 294-298, 2011.

[45] N. M. Gomez-Ortiz, W. S. Gonzalez Gomez, S. C. de la RosaGarcia et al., "Antifungal activity of $\mathrm{Ca}\left[\mathrm{Zn}(\mathrm{OH})_{3}\right]_{2} \quad 2 \mathrm{H}_{2} \mathrm{O}$ coatings for the presentation of limestone monuments: an in vitro study," International Biodeterioration and Biodegradation, vol. 91, pp. 1-8, 2014.

[46] J. F. Hernandez-Sierra, F. Ruiz, D. C. Cruz Pena et al., "The antimicrobial sensitivity of Streptococcus mutans to nanoparticles of silver, zinc oxide and gold," Nanomedicine, Nanotechnology, Biology, and Medicine, vol. 4, no. 3, pp. 237-240, 2008.

[47] J. F. Fernández Lozano, I. Lorite Villalba, F. Rubio Marcos et al., "Method for dry dispersion of nanoparticles and production of hierarchical structures and coatings," US Patent WO2010/010220 A1, 2014.

[48] Aerosil ${ }^{\circledR}$, Aeroxide $^{\circledR}$ and Sipernat ${ }^{\circledR}$ Products for the Construction Materials Industry, Technical Information 1398, Evonik Industries, Essen, Germany.

[49] I. Lorite, L. Pérez, J. J. Romero, and J. F. Fernández, "Effect of the dry nanodispersion procedure in the magnetic order of the $\mathrm{Co}_{3} \mathrm{O}_{4}$ surface," Ceramics International, vol. 39, no. 4, pp. 4377-4381, 2013.

[50] D. Alonso-Domínguez, I. Álvarez-Serrano, E. Reyes, and A. Moragues, "New mortars fabricated by electrostatic dry deposition of nano and microsilica additions: enhanced properties," Construction and Building Materials, vol. 135, pp. 186-193, 2017.

[51] E. Ghafari, S. A. Ghafari, Y. Feng, F. Severgnini, and N. Lu, "Effect of zinc oxide and Al-zinc oxide nanoparticles on the rheological properties of cement paste," Composites Part B: Engineering, vol. 105, pp. 160-166, 2016.

[52] G. Villain, M. Thiery, and G. Platret, "Measurement method of carbonation profiles in concrete: thermogravimetry, chemical analysis and gammadensimetry," Construction and Building Materials, vol. 37, no. 8, pp. 1182-1192, 2007.

[53] V. S. Ramachandran, R. M. Paroli, J. J. Beaudoin, and A. H. Delgado, Handbook of Thermal Analysis of Construction Materials, Noyes Publications/William Andrew Publishing, New York, NY, USA, 2003.

[54] A. Mellado, M. V. Borrachero, L. Soriano, J. Payá, and J. Monzó, "Immobilization of $\mathrm{Zn}(\mathrm{II})$ in Portland cement pastes," Journal of Thermal Analysis and Calorimetry, vol. 112, no. 3, pp. 1377-1389, 2013.

[55] M. Y. A. Mollah, J. P. Pargat, and D. L. Cocke, “An infrared spectroscopic examination of cement-based solidification/ stabilization systems-Portland Types V and IP with zinc," Journal of Environmental Science and Health, vol. 27, no. 6, pp. 1503-1519, 1992.

[56] M. A. Trezza, "Hydration study of ordinary Portland cement in the presence of zinc ions," Materials Research, vol. 10, no. 4, pp. 331-334, 2007.

[57] T. Vázquez Moreno, "Contribución al estudio de las reacciones de hidratación del cemento portland por espectroscopia infrarroja," Materiales de Construcción-CSIC, vol. 16, no. 163, pp. 51-63, 1976.

[58] F. Andrade Brehm, C. A. Mendes Moraes, R. C. Espinosa Modolo, A. C. Faria Vilela, and D. C. Coitinho Dal Molin, "Oxide zinc addition in cement paste aiming electric arc furnace," Construction and Building Materials, vol. 139, pp. 172-182, 2016.

[59] J. I. Tobón, J. J. Payá, M. V. Borrachero, and O. J. Restrepo, "Mineralogical evolution of Portland cement blended with silica nanoparticles and its effect on mechanical strength," Construction and Building Materials, vol. 21, pp. 1351-1355, 2007.

[60] B.-W. Jo, C.-H. Kim, G. Tae, and J.-B. Park, "Characteristics of cement mortar with nano- $\mathrm{SiO}_{2}$ particles," Construction and Building Materials, vol. 21, no. 6, pp. 1351-1355, 2007.

[61] A. M. Neville and J. J. Brooks, Concrete Technology, Longman Group, London, UK, 2nd edition, 2010.

[62] S. U. Al-Dulaijan, A.-H. Al-Tayyib, M. M. Al-Zahrani, G. Parry Jones, and A. I. Al-Mana, "Si MAS-NMR study of hydrated cement paste and mortar made with and without silica fume," Journal of the American Ceramic Society, vol. 78, no. 2, pp. 342-346, 1995. 


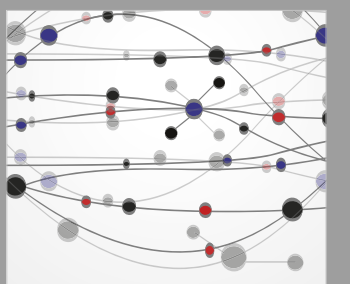

The Scientific World Journal
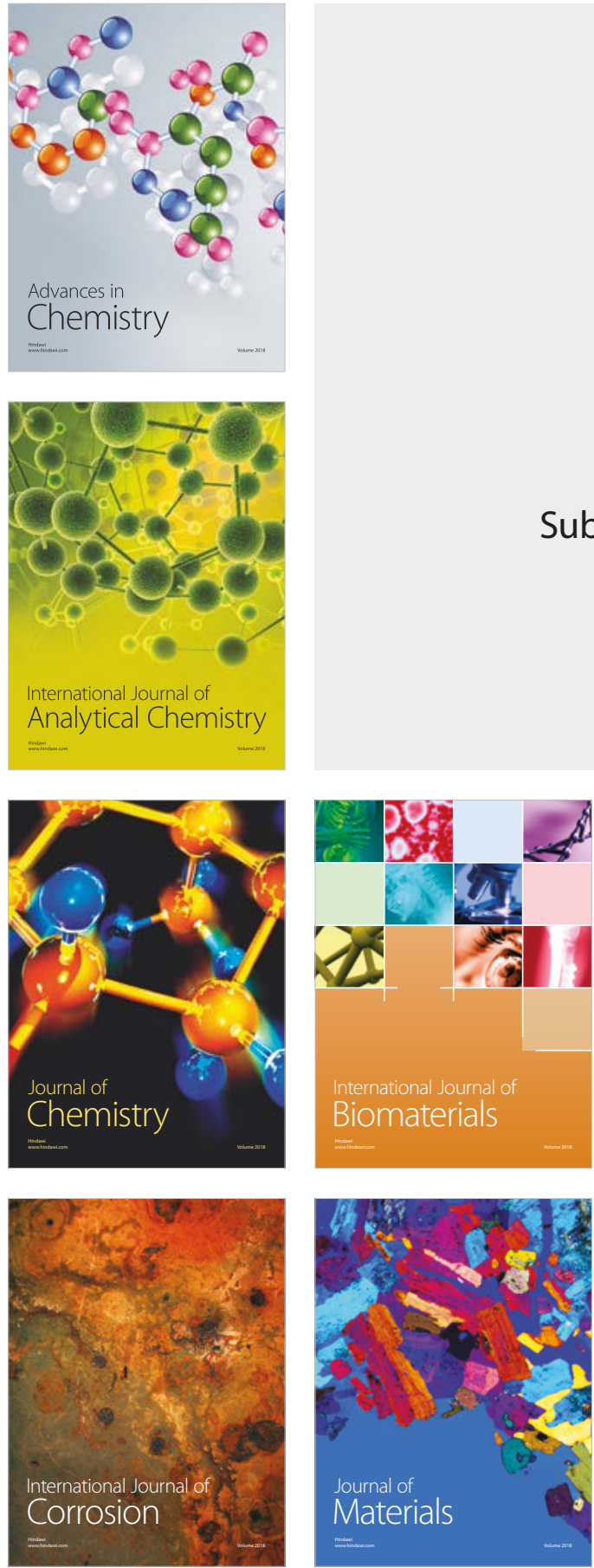

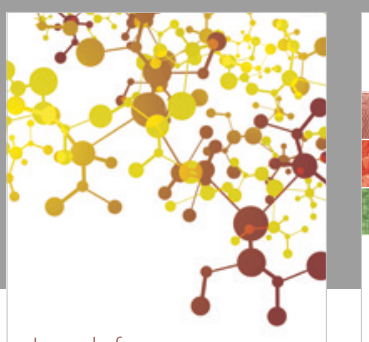

Journal of

Applied Chemistry
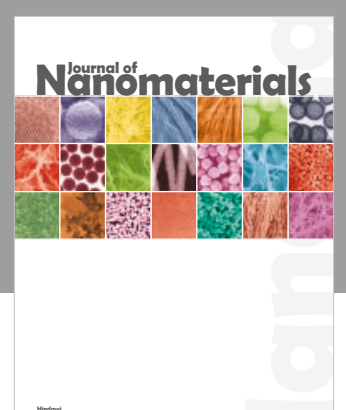

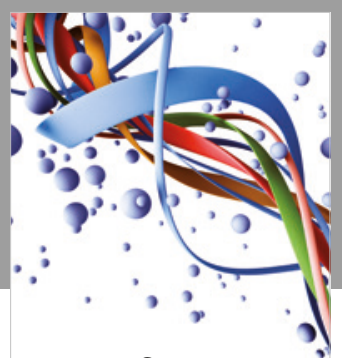

Scientifica

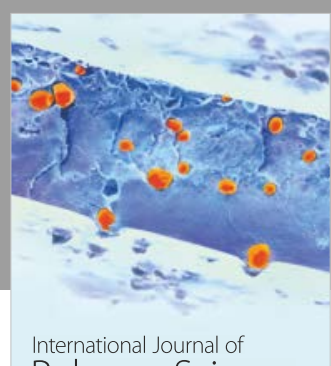

Polymer Science

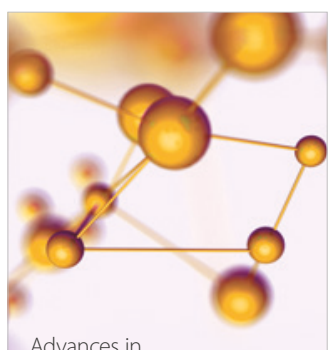

Physical Chemistry
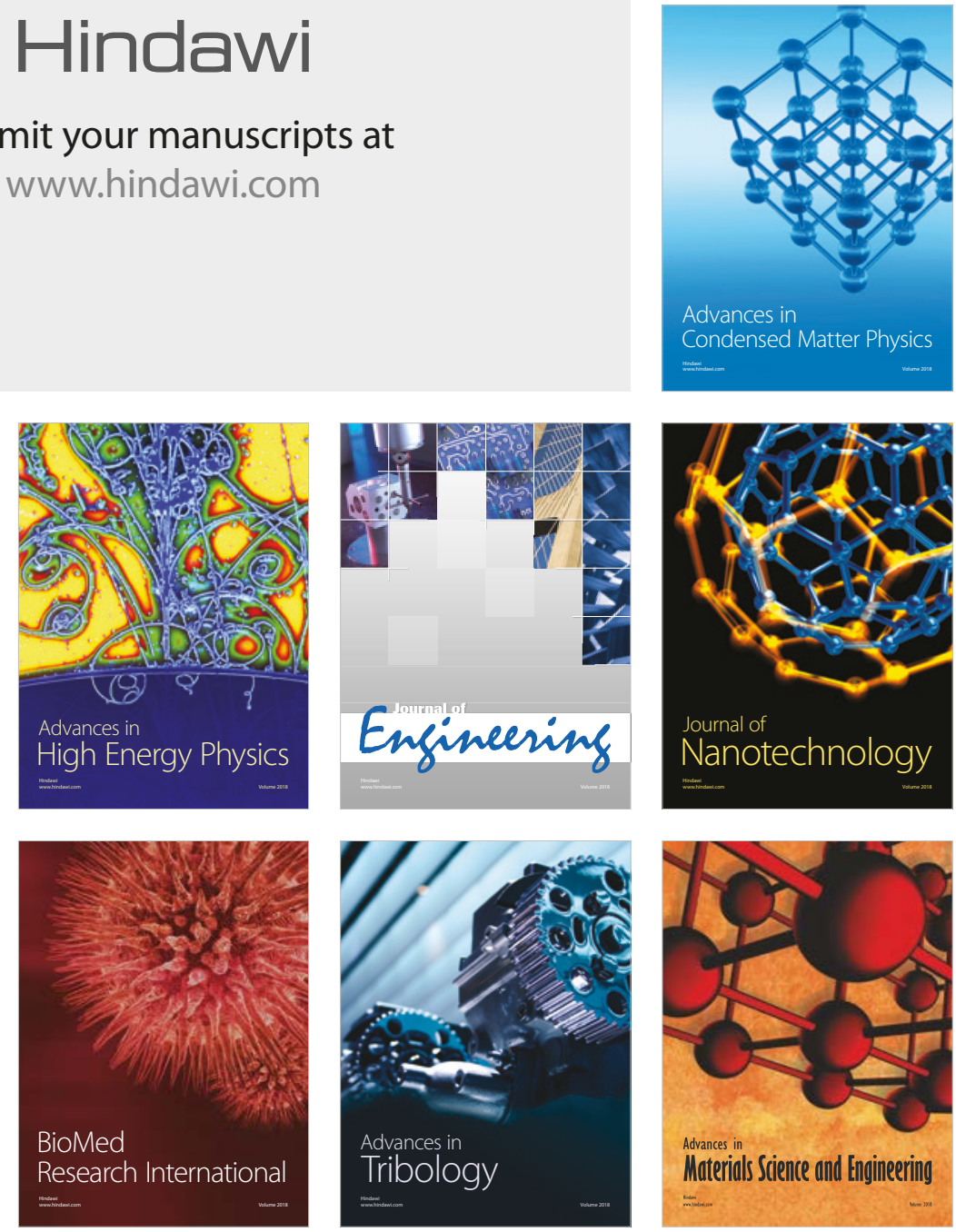